\title{
Studies on Ecological Monitoring of Plant Community and Plant Diversity in Shenzhen, Southern China
}

\author{
Yuyuan Huang1*, Xinfan Yu², Hong Liang2, Zhiming Yang1, Haiyang Wen², Zhen Ye ${ }^{3}$, Yunhe Lu', \\ Ruoyu Wei ${ }^{5}$, Lijun Yang ${ }^{2}$, Song Ma $^{2}$, Kangsai Zhao ${ }^{2}$, Fan Wang1, Zhijie Chen ${ }^{1}$, Huina Yang1,

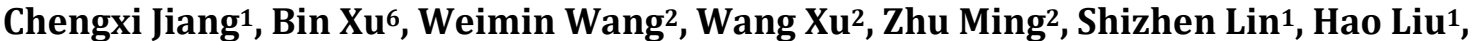 \\ Hualiang Luo', Suni Deng1, Lijuan Huang1, Yanjun Lei' ${ }^{1}$, Xiaoli Wan', Yahe Li' ${ }^{3}$, Wanmin Zhou', \\ Shun Zhao', Zhenliang Duan', Dongyao Liao', Xiaobo Qiu', Haoqun Huang", Linlin Jiang1 \\ ${ }^{1}$ College of Agriculture and Biology, Zhongkai University of Agriculture and Engineering, Guangzhou, China \\ ${ }^{2}$ Shenzhen Environmental Monitoring Center, Shenzhen, China \\ ${ }^{3}$ South China Institute of Environmental Sciences, Ministry of Ecology and Environment, Guangzhou, China \\ ${ }^{4}$ Environmental Monitoring Station of Nanshan District, Shenzhen, China \\ ${ }^{5}$ Ecological and Environmental Protection Monitoring Station of Dapeng District, Shenzhen, China \\ ${ }^{6}$ Construction Public Service Bureau of Dapeng New District, Shenzhen, China \\ Email: *huangyy233@126.com
}

How to cite this paper: Huang, Y. Y., Yu, X. F., Liang, H., Yang, Z. M., Wen, H. Y., Ye, Z., Lu, Y. H., Wei, R. Y., Yang, L. J., Ma, S., Zhao, K. S., Wang, F., Chen, Z. J., Yang, H. N., Jiang, C. X., Xu, B., Wang, W. M., Xu, W., Ming, Z., Lin, S. Z., Liu, H., Luo, H. L., Deng, S. N., Huang, L. J., Lei, Y. J., Wan, X. L., Li, Y. H., Zhou, W. M., Zhao, S., Duan, Z. L., Liao, D. Y., Qiu, X. B., Huang, H. Q., \& Jiang, L. L. (2021). Studies on Ecological Monitoring of Plant Community and Plant Diversity in Shenzhen, Southern China. Open Journal of Forestry, $11,352-380$.

https://doi.org/10.4236/ojf.2021.114022

Received: June 15, 2021

Accepted: October 17, 2021

Published: October 20, 2021

\begin{abstract}
From Jan. 2013 to Nov. 2018, we carried out the investigation on vegetation studies in the ecological monitoring programs, Shenzhen and totally researched 170 plant communities of mountain areas etc., few areas of street regions and parks etc., for communities' structural characteristics and plant diversity. We comparatively analyzed natural forests, semi-natural forest and artificial forest composition and structural characters and family, genus and species diversity level and the main affected factors. We also researched and analyzed these communities' structural characteristics and pant diversity, comparatively analyzed natural forests, semi-natural forest and artificial forest composition and structural characters and family, genus and species diversity level, the main affected factors; researched and analyzed the relationship between plant community structure characteristics with the absorbing ability to $\mathrm{PM}_{2.5}$ pollutants. The result showed that the structure and plant diversity of natural forest were obviously better than artificial disturbed forest or artificial forest, the semi-natural forest was the middle level of the forests, In the indices of height, $\mathrm{DBH}$, coverage and crow width etc. of tree layer, natural forests and semi-natural forests were obvious higher than that of artificial disturbed forest or artificial forest; in some forests of artificial disturbed forest or artificial forest, though their richness indices of family and
\end{abstract}


Copyright $\odot 2021$ by author(s) and Scientific Research Publishing Inc. This work is licensed under the Creative Commons Attribution International License (CC BY 4.0).

http://creativecommons.org/licenses/by/4.0/ genus were a slightly higher, but this contribution was majorly due to herb layer plants, and some shrub layer plants. Analyzing three kinds of communities, the number of tree layer species of natural forest was the largest, and their every $\alpha$-diversity index value was the highest; these characteristics values of semi-natural forest were second, artificial disturbed forests or artificial forests were the lowest; in shrub layer, and herb layer, few $\alpha$-diversity indices of artificial disturbed forest or artificial forest were a slightly higher than that of some natural forests, but the integral values of the diversity indices of natural forest and semi-natural forest were obviously higher than the former. The research showed that in the artificial disturbed forest or artificial forest, because there have some little scale clearing areas, so some pioneer plant species could enter the community and formed a temporarily increase of species diversity, however, these species major were some shrub and herb plants; but tree layer possessed obviously more, even surpassed several ten times biomass than shrub and herb layers. Therefore, the respects of maintain ecosystem stability and other ecological efficient have major and dominated position and so on; and then this community can be natural recovery and succession, those forementioned new entire plants shall withdraw from the community and are replaced by the original plants of the community; but this process has already caused the ecological efficient loss and ecosystem unstable. Above research results are better evidence and theory reference to the argument problems on that are natural forest and natural restoration forest biodiversity higher? or is artificial forest biodiversity higher? and or is more artificial disturbed forest higher? Our researches showed that used random investigation method set quadrats, and combined typical investigation method, the structural indices in the all layer of community and all diversity indices of tree, shrub and herb layers and the integral values were similar, same or usually these indices in the community which set $600 \mathrm{~m}^{2}, 800 \mathrm{~m}^{2}$ total quatrat area were higher ( $\alpha$-diversity) than that of more than $3000 \mathrm{~m}^{2}, 4000 \mathrm{~m}^{2}$ or $7000 \mathrm{~m}^{2}$, even more than $17,000 \mathrm{~m}^{2}$ total quadrat area of communities. These lots of researches further proved that according to minimum area method for vegetation survey, in subtropical region, using random investigation method combined with typical investigation set $400 \mathrm{~m}^{2}$ or $400 \mathrm{~m}^{2}-500 \mathrm{~m}^{2}$ total quadrat area in a community is correct, or $510-600 \mathrm{~m}^{2}$ quadrat is more stability to the investigation of plant community. The research showed that index values of plant diversity Shenzhen are higher than that of other some cities or some wild mountain areas, especially the natural forests are even higher than that of some other tropical natural conservation areas and some natural forests in other tropical regions. The researches identified that when analyzing a regional plant community biodiversity, if calculating only the species diversity, it shall understand only the species grade situation, so if need understand the diversity situation of whole nenutic level, not only calculate species diversity, but also need calculate the diversity of family, genus, and also need analyze combining the indices of diversity, evenness and richness of several grades of family, genus and species, it shall obtain more objective and round evaluation. The paper introduced some represented plant communities researched results and situations, pointed at 
the vegetation distribution status and some plant community component problems that the distribution pattern of vegetation in Shenzhen is that natural forest occupies a little proportion, some are semi-natural forest, about $70 \%$ proportion of city area is artificial forests in mountain area and parks, etc., ought to implement the effective measures to remold most of mountain artificial forests. The research identified that plant community has a good absorbed $\mathrm{PM}_{2.5}$ capability, therefore, reducing $\mathrm{PM}_{2.5}$ concentration in atmosphere, the better structure and diversity of community are the stronger absorbed $\mathrm{PM}_{2.5}$ capability it possesses. Authors proposed the suggestions on promoting and optimizing local vegetation composition elements and structure, so that raising plant diversity and the biomass of plant communities in each area, improving ecological environment and optimizing ecosystem.

\section{Keywords}

Shenzhen, Vegetation, Community, Structure, Diversity, $\mathrm{PM}_{2.5}$, Ecological Monitoring, Natural Forest, Artificial Forest

\section{Introduction}

In order to respond the call of Shenzhen Government for constructing ecological city, in Oct. 2006, Shenzhen Environmental Monitoring Center combined with Zhongkai University of Agriculture and Engineering put forwarded constructing ecological monitoring network system in whole city scope (the first author as all application materials writer and the master planner of the project), obtained government supported and investment in 2007, constructed 5 ecological monitoring stations in 5 Districts and New Districts of Dapeng, Futian, Baoan, Pingshan and Nanshan, Shenzhen.

In former, about the vegetation structure of Shenzhen and plant diversity have carried out some researches, Liu et al. (2007) investigated to Acacia mangium plantation in Phoenix Mountain; Liu et al. (2010) carried out research to the structure of community of Danan Mountain; Zhang et al. (2007) carried out study on diversity of Syzygium odoratum community in Dapeng Peninsula, Shenzhen; Kang et al. (2005) made investigation about plant type and community characteristic in Bijiangshan Park, Shenzhen; Wang et al. (2003) researched on the species diversity and succession situation of natural forest communities in Nanshan District of Shenzhen. Above researches all are admeasurement and analysis on several or about ten communities in narrower scale; because the plant community is successional and variable, so need make wider scale and more plant community researches, and then can understand the situation of dynamics and composition and biodiversity of the vegetation. From Jan. 2013, our organizations carried out ecological monitoring in respect of plant, insect, higher animal and microbe, then continued to take many other areas measures and researches, especially carried out lots of vegetation ecology researches, collected 
many of plant specimens and built the data bases of plants and animals. In aspect of plant community and diversity research, until 2018, we totally made 170 communities researches. In this paper, we focus on introducing a part of the research situation of the communities. These researches are importantly significant and theory reference to exploring the status of ecosystem structure, tracking monitoring the change trends of these biological characters and factors, and plant ecology, phytogeography, ecological monitoring research, and the strategy draw up on optimization of local ecosystem protection.

\section{Study Areas and Methods}

\subsection{Study Areas}

Shenzhen is a coastal city in South China, neighboring Hong Kong and Macao, and has been an important window of China's reform and opening up, and the important economic developed city, its longitude lies between $113^{\circ} 43^{\prime}$ and $114^{\circ} 38^{\prime} \mathrm{E}$, and its latitude between $22^{\circ} 24^{\prime}$ and $22^{\circ} 52^{\prime} \mathrm{N}$. The total area of Shenzhen is $1997.47 \mathrm{~km}^{2}$, it has 310 rivers and streams associated with the nine hydrographic systems and has sea area of $1145 \mathrm{~km}^{2}$, boasts $260 \mathrm{~km}$ of coastline. It has a subtropical monsoon climate. Its weather is generally temperate to mild, with plenty of rain and sunshine. The annual average temperature is $23^{\circ} \mathrm{C}$. The average annual rainfall totals $1935.8 \mathrm{~mm}$ and the average yearly number of hours of sunshine is 1837.6 .

From Jan. 2013 to now, we carried out investigation on vegetation studies in the ecological monitoring programs, Shenzhen, until June. 2017, we have made the investigation studies of 122 communities in every kind green gland; since Aug. 2017 to May 2018, carried out 5 communities in Paiya mountain, 13 communities in Baguang region, and 30 communities in Yangmeikeng, Shenzhen, total 170 communities; made comparative researches to natural forest, semi-natural forest, artificial forest in mountain areas, street regions and beach mangrove communities. Figure 1 is the 170 communities distributed situation.

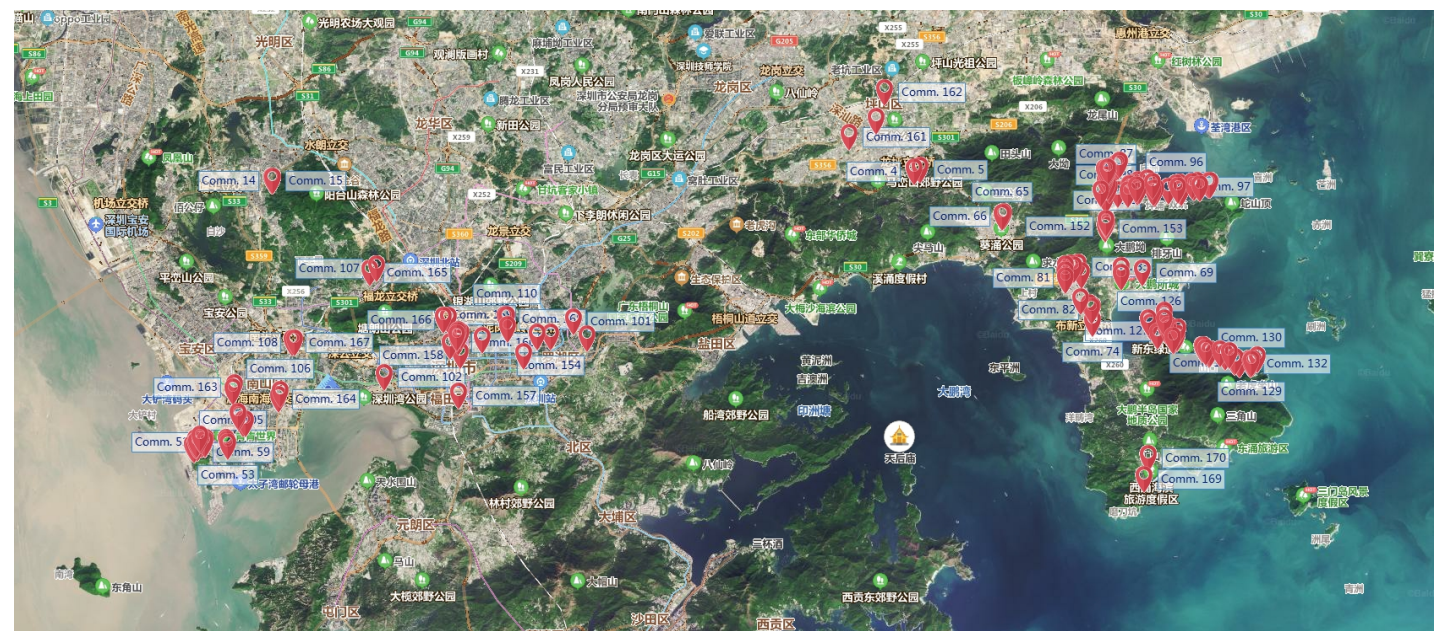

Figure 1. The geographical distribution situation of 170 plant communities in Shenzhen. 
In 170 communities, among 15 communities whose located in 5 ecological monitoring stations in 5 District and New Districts were main and center research areas and communities, other communities were as the vegetation research system network sites, so that observed and analyzed their change trends and effect relation each other. The main 15 communities geographical distribution situation see Figure 2, their places and community name as follow:

Yangmeikeng, Qiniangshan, this station is the center monitoring station, several communities geographical distribution and community name situation: Comm. 1: Macaranga sampsonii-Rhodomyrtus tomentosa-Carex cruciata, $114^{\circ} 34^{\prime} 55.10^{\prime \prime} \mathrm{E}, 22^{\circ} 32^{\prime} 25.79^{\prime \prime N}$, altitude $110 \mathrm{~m}$; Comm. 2: Machilus velutina-Psychotria rubra-Iantum capillus-junonis, $114^{\circ} 34^{\prime} 25.84^{\prime \prime} \mathrm{E}, 22^{\circ} 32^{\prime} 36.55^{\prime \prime} \mathrm{N}$, altitude $125 \mathrm{~m}$; Comm. 3: Alstonia scholaris-Psychotria rubra-Adiantum capillus-junonis: $14^{\circ} 34^{\prime} 28.20^{\prime \prime} \mathrm{E}, 22^{\circ} 32^{\prime} 41.44^{\prime \prime} \mathrm{N}$, altitude $180 \mathrm{~m}$.

Chiao, Tianxin Mountain located in Pingshan Town, Shenzhen, the mountain located on the side a reservoir, chose 2 hill area communities: Comm.1, Litchi chinensis-Schefflera minutistellata-Blechnum orientale community, $22^{\circ} 39^{\prime} 10^{\prime \prime} \mathrm{N}$, $114^{\circ} 23^{\prime} 35^{\prime \prime E}$, altitude $72 \mathrm{~m}$, Comm. 2, Eucalyptus robusta-Rhodomyrtus tomentosa-Dicranopteris pedata community, $22^{\circ} 39^{\prime} 29^{\prime \prime} \mathrm{N}, 114^{\circ} 23^{\prime} 57^{\prime \prime} \mathrm{E}$, altitude $85 \mathrm{~m}$.

Yangtai Mountain: Comm. 1: Litchi chinensis-Ilex asprella-Blechnum orientale, $22^{\circ} 39^{\prime} 19.73^{\prime \prime} \mathrm{N}, 113^{\circ} 55^{\prime} 49.61^{\prime \prime E}$, altitude $108 \mathrm{~m}$. Comm. 2, 22 $39^{\circ} 20.84^{\prime \prime} \mathrm{N}$, $113^{\circ} 55^{\prime} 47.91$ "E, altitude $94 \mathrm{~m}$.

Xiaonanshan: Comm. 1: Microcos paniculata-Fissistigma oldhamii-Ophiopogon bodinieri, $22^{\circ} 29^{\prime} 29.89^{\prime \prime} \mathrm{N}, 113^{\circ} 52^{\prime} 52.84 " \mathrm{E}$, altitude $82 \mathrm{~m}$; Comm.2: Schefflera minutistellata-Ficus hirta Vahl-Blechnum orientale, $22^{\circ} 29^{\prime} 25.61^{\prime \prime} \mathrm{N}, 113^{\circ} 52^{\prime} 54.68^{\prime \prime} \mathrm{E}$, altitude $105 \mathrm{~m}$; Comm.3: Dalbergia odorifera-Sterculia lanceolat-Dicranopteris pedata, $22^{\circ} 29^{\prime} 18.46^{\prime \prime} \mathrm{N}, 113^{\circ} 53^{\prime} 04.09 " \mathrm{E}$, altitude $159 \mathrm{~m}$.

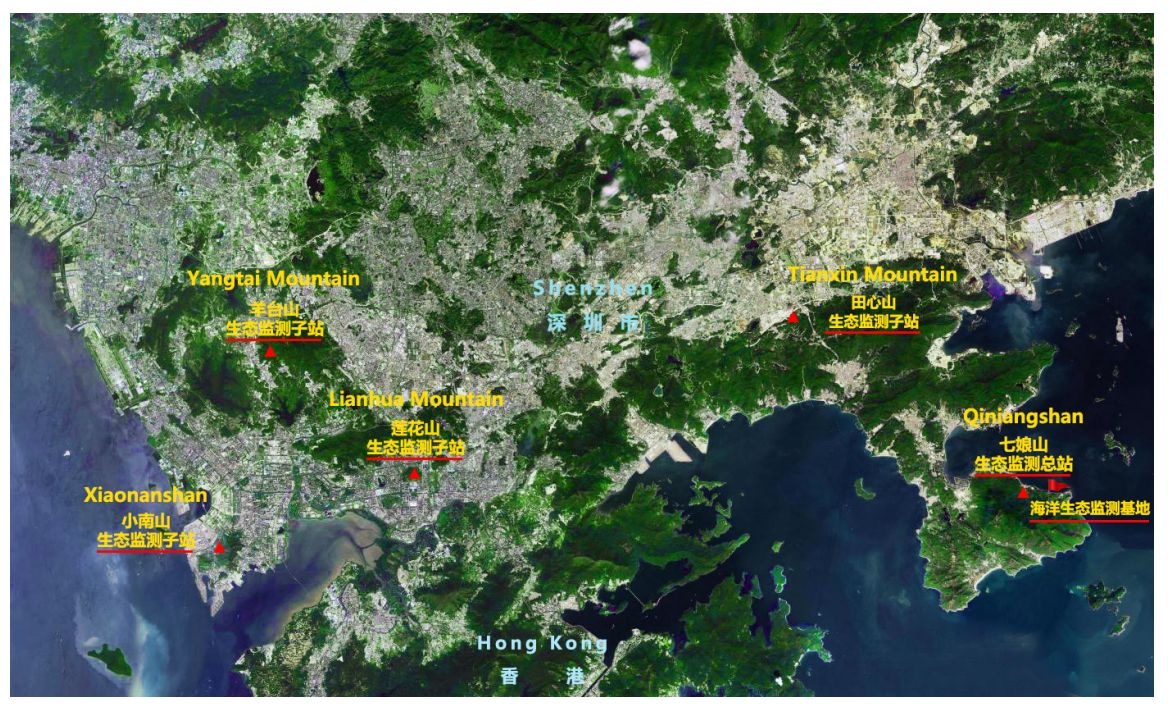

Figure 2. The geographical distributed map of 5 study areas in Ecological Monitoring System, Shenzhen. 
Lianhua Mountain, Comm. 1: Ficus benjamina + Ficus microcarpa-Rhododendron simsii-Pteris semipinnata, $22^{\circ} 33^{\prime} 19.15^{\prime \prime} \mathrm{N}, 114^{\circ} 03^{\prime} 20.15^{\prime \prime} \mathrm{E}$; Comm. 2: Acacia confuse + Dalbergia benthami-Psychotria rubra-Pteris semipinnata, $22^{\circ} 33^{\prime} 22.36^{\prime \prime} \mathrm{N}, 114^{\circ} 03^{\prime} 17.72^{\prime \prime} \mathrm{E}$, Comm. 3: Acacia confuse-Ilex asprella-Pteris semipinnata, $22^{\circ} 33^{\prime} 25.68^{\prime \prime} \mathrm{N}, 114^{\circ} 03^{\prime} 19.61^{\prime \prime E}$, Comm. 4: Albizia falcataria-Psychotria rubra-Blechnum orientale, $22^{\circ} 33^{\prime} 28.82^{\prime \prime} \mathrm{N}, 114^{\circ} 03^{\prime} 27.63^{\prime \prime} \mathrm{e}$, Comm. 5: Acacia confuse-Alstonia scholaris-Nephrolepis auriculata, $22^{\circ} 33^{\prime} 26.95^{\prime \prime} \mathrm{N}, 114^{\circ} 03^{\prime} 16.74^{\prime \prime E}$.

In 2015, Environment Monitoring Main Station of China set Ground and Fixed Point Ecological Monitoring Station of Unban Ecosystem in this ecological monitoring central station of Shenzhen; Now, there set a National Environmental Sciences Observation and Research Station, Ministry of Ecology and Environment of China, it is one of eight the construction stations of the first batch in China, and a National Field Science Observation and Research Station, Ministry of Science and Technology of China.

\subsection{Measure Methods}

According to minimum area method for vegetation survey, in subtropical region, using random investigation method, then the total quadrat area of every community are $400 \mathrm{~m}^{2}$ (Zhang, 2011), it has gratified the demand to investigate and understand the all species of the community, so, more scholars used $400 \mathrm{~m}^{2}$ or more than the area that were $410-600 \mathrm{~m}^{2}$ (Gao et al., 1997; Grobler et al., 2002; Zhu et al., 2004; Huang et al., 2007; Ortega-Álvarez et al., 2011; Turner et al., 2012). In these researches, random investigation method was used combined with typical investigation method set quadrats, the total quadrat area of every community were more than $600-2000 \mathrm{~m}^{2}$, few reached 3500 - $7600 \mathrm{~m}^{2}$ as comparative research, one reached $17,500 \mathrm{~m}^{2}$; every community investigation was no less than 3 quadrats, every quadrat size from 100 to 300 $\mathrm{m}^{2}$. Measured and recorded species name, individual number, plant height, $\mathrm{DBH}$ (only tree), coverage of tree, shrub, and herb layers, so that to understand the situation of dominant species of every layer of communities. The shrub layer set up four to six smaller quadrats inside every big quadrat, with every little quadrat area $4 \times 4 \mathrm{~m}$; the herb layer set up four $1 \times 1 \mathrm{~m}$ little quadrats inside every shrub layer quadrat. Higher than $4 \mathrm{~m}$ individuals were divided into tree layer, under $4 \mathrm{~m}$ individuals were divided into shrub layer (include the seeding of tree). Then calculated and analyzed diversity, evenness, and richness indices.

\subsection{Data Analysis}

\section{Important value index}

The calculate formula of tree layer of important value

Important value

$=$ Relative density + Relative frequency + Relative dominance

Or: Important value 
$=($ Relative density + Relative frequency + Relative dominance $) / 300$

The calculate formula of shrub and herb layer of important value

Important value

$=$ Relative density + Relative frequency + Relative coverage

Or: Important value

$=($ Relative density + Relative frequency + Relative coverage $) / 300$

\section{Diversity indices}

1) Simpson index of species

$$
D=1-\sum_{i=1}^{s} \frac{N_{i}\left(N_{i}-1\right)}{N(N-1)} \quad(i=1,2, \cdots, n) \quad(\text { as same at below) }
$$

In the formula, $S$ is the number of species, $N_{i}$ is the number of individuals of species $i$, and $N$ is the number of individuals of all species. The index is only used to calculate the species diversity, and is not related to any diversity situation on family and genus.

The Simpson index of improved pattern of species is expressed as follows:

$$
D_{s}=1-\sum_{i=1}^{s} \frac{N_{s i}\left(N_{s i}-1\right)}{N_{s}\left(N_{s}-1\right)}
$$

$S$ is the number of species, $N_{s}$ is the number of individuals of all species, $N_{s i}$ is the number of individual species $i$.

Where $S$ is the number of species, $N_{s}$ is the number of individuals of all species, and $N_{s i}$ is the number of individual species $i$.

2) Index of genus diversity (Huang et al., 2016a, 2017; Liang et al., 2016):

$$
\begin{gathered}
D_{g 1}=1-\sum_{i=1}^{g} \frac{N_{g i}\left(N_{g i}-1\right)}{N_{g}\left(N_{g}-1\right)} \\
D_{g 2}=1-\sum_{i=1}^{g}\left(\frac{N_{g i}}{N_{g}}\right)^{2}
\end{gathered}
$$

Here $N_{g i}$ is the number of species which belongs to genus $i, N_{g}$ is the number of all genera, and $D_{g}$ is the index of genera diversity. If there is only one species and one genus in one community, the numerator and denominator should not be subtracted with 1 .

3) Index of family diversity (Huang et al., 2016a, 2017; Liang et al., 2016):

$$
\begin{gathered}
D_{f 1}=1-\sum_{i=1}^{f} \frac{N_{f i}\left(N_{f i}-1\right)}{N_{f}\left(N_{f}-1\right)} \\
D_{f 2}=1-\sum_{i=1}^{f}\left(\frac{N_{f i}}{N_{f}}\right)^{2}
\end{gathered}
$$

where $f$ is the number of family, $N_{f}$ is the number of all families, $N_{f i}$ is the number of genus which belongs to family $i$, and $D_{f}$ is the diversity index of family of community. If there is only one species and one genus in one community, the numerator and denominator should not be subtracted with 1 . 
4) Composite diversity index (Huang et al., 2017):

$$
\begin{aligned}
& D_{c 1}=D_{f 1}+D_{g 1}+D_{s} \\
& D_{c 2}=D_{f 2}+D_{g 2}+D_{s}
\end{aligned}
$$

where $D_{c 1}$ and $D_{c 2}$ are the composite diversity indices of community, $D_{f 1}$ and $D_{f 2}$ are the diversity indexes of families, $D_{g 1}$ and $D_{g 2}$ are the diversity indices of genus, and $D_{s}$ is the diversity index of species (it is not any layer (as tree, herb) index, and is integral value; When $D_{c}$ is high, the diversity of the community level is also high; meanwhile, the values of $D_{f}, D_{f 2}$ and $D_{g 1}, D_{g 2}, D_{s}$, and their proportion shall show the diversity composition situation. Only when every value of $D_{f}$, $D_{g}$, or $D_{s}$ are all high, and near equality of their proportion, the community biodiversity is optimum. If only the $D_{s}$ value is high, or only the $D_{g}$, and the other two values are low, the diversity of the community is also low even if the $D_{c}$ value is high.

5) Shannon-Wiener index

$$
H=-\sum_{i=1}^{s} P_{i} \ln P_{i}
$$

Here $S$ is the number of species, $P_{i}$ is the ratio of species $i$ individuals in all individuals, and $H$ is the species diversity index.

Richness indices

1) Species richness index

$$
\begin{gathered}
\text { Odum index: } R_{s 1}=\frac{S}{\ln N} \\
\text { Menhinnick index: } R_{s 2}=\frac{\ln S}{\ln N}
\end{gathered}
$$

Here $S$ is the species index, and $N$ is the number of whole species individuals.

2) Genus richness (Huang et al., 2017):

$$
\begin{gathered}
R_{g 1}=G \\
R_{g 2}=\frac{G}{\ln S}
\end{gathered}
$$

where $G$ is the number of genus, and $S$ is the number of species; the formula shows that the higher the $S$ value, the lower the diversity, such as in a community in which every genus possessed more species, the whole community will have lower genus diversity. If the number of genera in two communities is the same but each genus comprises one species in community 1 , the genus diversity of this community is higher. If each genus includes more than one species or most of the genera contain one species and one or two genera are composed of more than two species in community 2 , then its genus diversity is lower than that of community 1.

3) Family richness (Huang et al., 2016a, 2017; Liang et al., 2016):

$$
R_{f 1}=F
$$




$$
R_{f 2}=\frac{\ln F}{\ln G}
$$

$F$ is the number of families while $G$ is the number of genera. The formula shows that when $G$ is higher, diversity is lower. In a community, when each family had more genera, the whole community had lower family diversity. Thus, if the number of families in the two communities was the same, but each family had a genus only in community A, then the family diversity of this community was higher. However, if every family had more than one genus or if most of the families had one genus, but one to two families had more than two species in community B, its diversity was lower than community A.

\section{Pielou evenness index:}

$$
\begin{gathered}
J=\frac{H}{\ln S} \\
H=-\sum\left[\left(\frac{N_{i}}{N}\right) \ln \left(\frac{N_{i}}{N}\right)\right]
\end{gathered}
$$

In the formula, $S$ is the number of species, $N_{i}$ is the individual number of species $i$, and $N$ is the individual number of all species in one layer.

\section{Similarity coefficient ( $\beta$-diversity index)}

1) The similarity coefficient of species (improved pattern) is obtained as follows:

$$
C_{s}=\frac{2 N_{s}}{a_{s}+b_{s}}
$$

$N_{s}$ is the number of species commonly existing in communities A and B, $a_{s}$ is the number of species in community $\mathrm{A}, b_{s}$ is the number of species in community B, and $C_{s}$ is the similarity coefficient of species.

2) The similarity coefficient of genera in a community is obtained as follows (Huang et al., 2016a, 2017):

$$
C_{g}=\frac{2 N_{g}}{a_{g}+b_{g}}
$$

$N_{g}$ is the number of genera commonly existing in communities A and B, $a_{g}$ is the number of genera in community $\mathrm{A}, b_{g}$ is the number of genera in community B, and $C_{g}$ is the similarity coefficient of genera.

3) The similarity coefficient of families in a community is obtained as follows (Huang et al., 2016a, 2017):

$$
C_{f}=\frac{2 N_{f}}{a_{f}+b_{f}}
$$

$N_{f}$ is the number of families commonly existing in communities A and B, $a_{f}$ is the number of families in community $\mathrm{A}, b_{f}$ is the number of families in community B, and $C_{f}$ is the similarity coefficient of families.

4) Synthetic similarity coefficient of family, genus, and species is obtained as follows (Huang et al., 2016a, 2017): 


$$
\beta_{c}=\frac{2\left(N_{f}+N_{g}+N_{s}\right)}{\left(N_{f a}+N_{g a}+N_{s a}\right)+\left(N_{f b}+N_{g b}+N_{s b}\right)}
$$

$\beta_{c}$ is the synthetic similarity coefficient of family, genus, and species, $N_{f}$ is the number of common families in the two communities, $N_{g}$ is number of common genera in the two communities, $N_{s}$ is the number of common species in the two communities, $N_{f a}$ is the number of families in community A, $N_{g a}$ is the number of genera in community A, $N_{s a}$ is the number of species in community A. $N_{f b}$ is number of families in community B, $N_{g b}$ is the number of genera in community $\mathrm{B}$, and $N_{s b}$ is the number of species in community B.

\section{Results}

\subsection{The Characteristics of Plant Community}

In all 170 plant communities, the basic measured data that are indices of average height, average DBH (only tree), coverage, relative dominance, relative density, relative frequency and important value were calculated.

Such as our research to the characteristics of one plant community in northern slope of Xiaonanshan see Tables 1-3.

All researched 170 communities were made above these community characteristics indices calculations, each community had 3 the characters tables, total 510 data tables. Meanwhile, each community carried out family, genus and species number, and their subordination relation analyzed, about 200 tables or figures.

The all plant communities were carried out comprehensive indices statistic and analysis. Such as the composition statistical analysis to species number in every layer of the 25 plant communities of Baguang region of Dapeng New

Table 1. The structural characteristics of tree layer of Microcos paniculata-Fissistigma oldhamii-Ophiopogon bodinieri community of Xiaonanshan.

\begin{tabular}{|c|c|c|c|c|c|c|c|c|}
\hline Species name & Number & $\begin{array}{l}\text { Average height } \\
\text { (m) }\end{array}$ & $\begin{array}{l}\mathrm{DBH} \\
(\mathrm{cm})\end{array}$ & $\begin{array}{c}\text { Coverage } \\
(\%)\end{array}$ & $\begin{array}{c}\text { Relative } \\
\text { dominance }\end{array}$ & $\begin{array}{l}\text { Relative } \\
\text { density }\end{array}$ & $\begin{array}{l}\text { Relative } \\
\text { frequency }\end{array}$ & $\begin{array}{c}\text { Importance } \\
\text { value }\end{array}$ \\
\hline Microcos paniculata & 72 & 6.3 & 9.2 & 2.35 & 51.31 & 49.32 & 0.13 & 0.36 \\
\hline Sterculia lanceolata & 4 & 7.8 & 15.4 & 0.21 & 4.59 & 32.88 & 0.13 & 0.17 \\
\hline Litsea glutinosa & 1 & 10 & 20 & 0.08 & 1.75 & 2.74 & 0.07 & 0.03 \\
\hline Millettia pulchra & 48 & 5.6 & 9.5 & 1.37 & 29.91 & 0.68 & 0.13 & 0.15 \\
\hline Triadica cochinchinensis & 1 & 4 & 7.7 & 0.01 & 0.22 & 0.68 & 0.07 & 0.02 \\
\hline Archidendron clypearia & 1 & 6 & 13 & 0.03 & 0.66 & 0.68 & 0.07 & 0.03 \\
\hline Millettia oraria & 1 & 8 & 13 & 0.09 & 1.97 & 0.68 & 0.07 & 0.03 \\
\hline Aporosa dioica & 2 & 5 & 5.8 & 0.04 & 0.87 & 1.37 & 0.07 & 0.03 \\
\hline Alstonia scholaris & 9 & 4.7 & 9.6 & 0.19 & 4.15 & 6.16 & 0.07 & 0.08 \\
\hline Akebia quinata & 5 & 6.2 & 8.8 & 0.13 & 2.84 & 3.45 & 0.07 & 0.04 \\
\hline Syzygium araiocladum & 1 & 4.5 & 9.6 & 0.02 & 0.44 & 0.68 & 0.07 & 0.03 \\
\hline Macaranga tanarius & 1 & 4.5 & 12 & 0.06 & 1.31 & 0.68 & 0.07 & 0.03 \\
\hline
\end{tabular}


Table 2. The structural characteristics of shrub layer of Microcos paniculata-Fissistigma oldhamii-Ophiopogon bodinieri community of Xiaonanshan.

\begin{tabular}{|c|c|c|c|c|c|c|c|}
\hline Species name & Number & $\begin{array}{c}\text { Average height } \\
\text { (m) }\end{array}$ & $\begin{array}{c}\text { Coverage } \\
(\%)\end{array}$ & $\begin{array}{l}\text { Relative } \\
\text { coverage }\end{array}$ & $\begin{array}{l}\text { Relative } \\
\text { density }\end{array}$ & $\begin{array}{l}\text { Relative } \\
\text { frequency }\end{array}$ & $\begin{array}{l}\text { Important } \\
\text { value }\end{array}$ \\
\hline Ardisia crenata & 3 & 50.67 & 0.06 & 1.79 & 6.82 & 6.06 & 0.05 \\
\hline Zanthoxylum avicennae & 1 & 19.00 & 0.00 & 0.07 & 2.27 & 3.03 & 0.02 \\
\hline Sterculi alanceolata & 6 & 59.67 & 0.19 & 5.45 & 13.64 & 12.12 & 0.10 \\
\hline Psychotria asiatica & 3 & 99.67 & 0.28 & 7.94 & 6.82 & 9.09 & 0.08 \\
\hline Aporosa dioica & 2 & 52.00 & 0.10 & 2.95 & 4.55 & 6.06 & 0.05 \\
\hline Evodia lepta & 4 & 88.25 & 0.47 & 13.39 & 9.09 & 12.12 & 0.12 \\
\hline Bridelia tomentosa & 1 & 145.00 & 0.04 & 1.20 & 2.27 & 3.03 & 0.02 \\
\hline Ficus hirta & 2 & 137.50 & 0.20 & 5.53 & 4.55 & 6.06 & 0.05 \\
\hline Microcos paniculata & 1 & 240.00 & 0.04 & 1.22 & 2.27 & 3.03 & 0.02 \\
\hline Schefflera minutistellata & 6 & 61.67 & 0.24 & 6.78 & 13.64 & 12.12 & 0.11 \\
\hline Fissistigma oldhamii & 5 & 170.00 & 1.03 & 29.16 & 11.36 & 9.09 & 0.17 \\
\hline Baeckea frutescens & 1 & 179.00 & 0.11 & 3.18 & 2.27 & 3.03 & 0.03 \\
\hline Litsea rotundifolia var. oblongifolia & 1 & 122.00 & 0.05 & 1.43 & 2.27 & 3.03 & 0.02 \\
\hline Celtis sinensis & 5 & 110.80 & 0.29 & 8.27 & 11.36 & 6.06 & 0.09 \\
\hline Berchemia lineata & 3 & 143.33 & 0.41 & 11.64 & 6.82 & 6.06 & 0.08 \\
\hline
\end{tabular}

Table 3. The structural characteristics of herb layer of Microcos paniculata-Fissistigma oldhamii-Ophiopogon bodinieri community of Xiaonanshan.

\begin{tabular}{|c|c|c|c|c|c|c|c|}
\hline Species name & Number & $\begin{array}{l}\text { Average height } \\
(\mathrm{cm})\end{array}$ & $\begin{array}{c}\text { Coverage } \\
(\%)\end{array}$ & $\begin{array}{l}\text { Relative } \\
\text { coverage }\end{array}$ & $\begin{array}{l}\text { Relative } \\
\text { density }\end{array}$ & $\begin{array}{l}\text { Relative } \\
\text { frequency }\end{array}$ & $\begin{array}{l}\text { Important } \\
\text { value }\end{array}$ \\
\hline Ophiopogon bodinieri & 4 & 20.00 & 5.65 & 23.56 & 14.81 & 15 & 0.18 \\
\hline Uvaria macrophylla & 1 & 75.00 & 4.41 & 18.39 & 3.70 & 5 & 0.09 \\
\hline Liriope spicata & 2 & 27.50 & 5.15 & 21.48 & 7.41 & 10 & 0.13 \\
\hline Pandanus tectorius & 2 & 165.00 & 0.02 & 0.08 & 7.41 & 10 & 0.06 \\
\hline Cibotium barometz & 1 & 75.00 & 0.05 & 0.21 & 3.70 & 5 & 0.03 \\
\hline Smilax china & 2 & 70.00 & 0.85 & 3.54 & 7.41 & 10 & 0.07 \\
\hline Chrysopogon aciculatus & 6 & 63.17 & 6.99 & 29.15 & 22.22 & 5 & 0.19 \\
\hline Hypolytrum nemorum & 2 & 58.00 & 0.71 & 2.96 & 7.41 & 10 & 0.07 \\
\hline Zanthoxylum nitidum & 2 & 50.00 & 0.05 & 0.21 & 7.41 & 10 & 0.06 \\
\hline Lonicera pampaninii & 2 & 27.50 & 0.04 & 0.17 & 7.41 & 10 & 0.06 \\
\hline Wisteria sinensis & 1 & 10.00 & 0.04 & 0.17 & 3.70 & 5 & 0.03 \\
\hline Scleria hebecarpa & 2 & 41.00 & 0.02 & 0.08 & 7.41 & 5 & 0.04 \\
\hline
\end{tabular}

District, Shenzhen, among 3 communities is mangrove forest, the species number of 20 land and offshore communities see Figure 3.

The height of all 25 communities see Figure 4. 


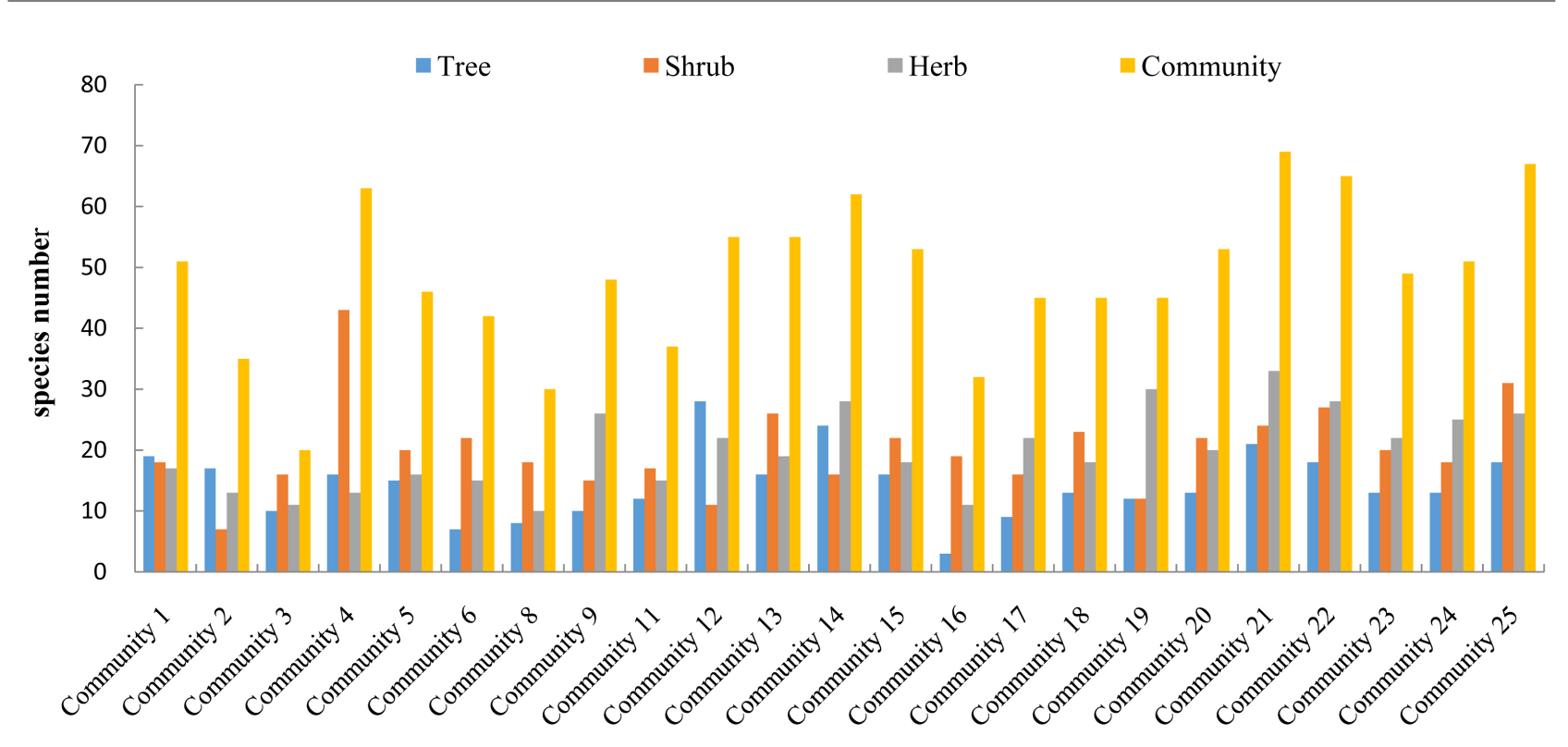

Figure 3. The species number of different layer of Baguang region of 20 plant communities.

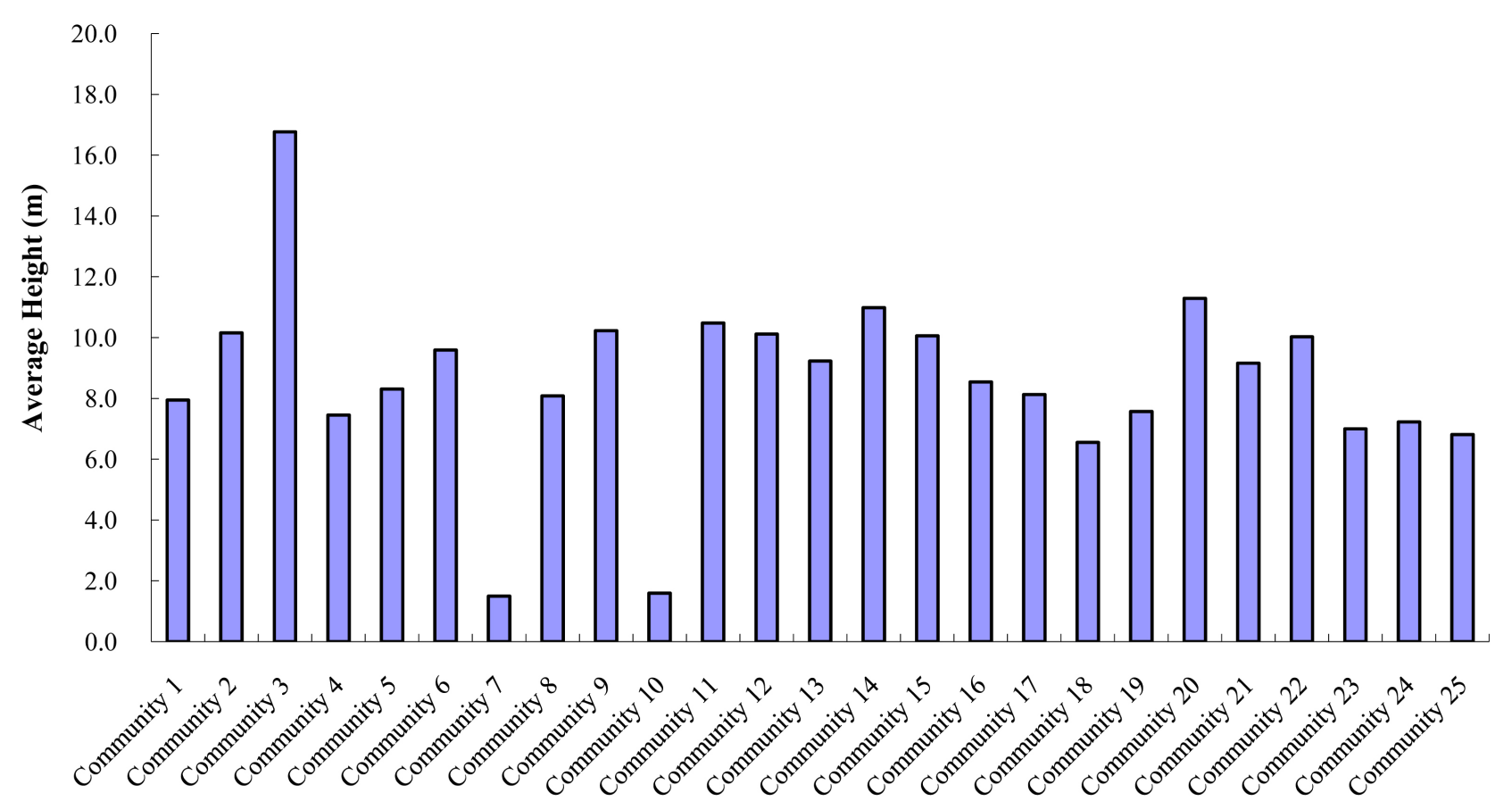

Figure 4. The average height of tree of 25 plant communities in Baguang region.

Seen Figure 3, in community 2, community 3, community 6, community 9 , community 11 , community 12 , community 14 , community 15 , community 20 , community 21 , community 22 , their height of tree were ranger high.

The coverage values of 23 plant communities (it not includes 2 mangrove forests, but some communities are semi-mangrove forest) in Baguang see Figure 5.

Seen Figure 5, many coverage values of tree layer of communities reached $150 \%-300 \%$ in the community, showed that there' trees have a good development; in many communities, the integral index of coverage reached $380 \%-500 \%$. 


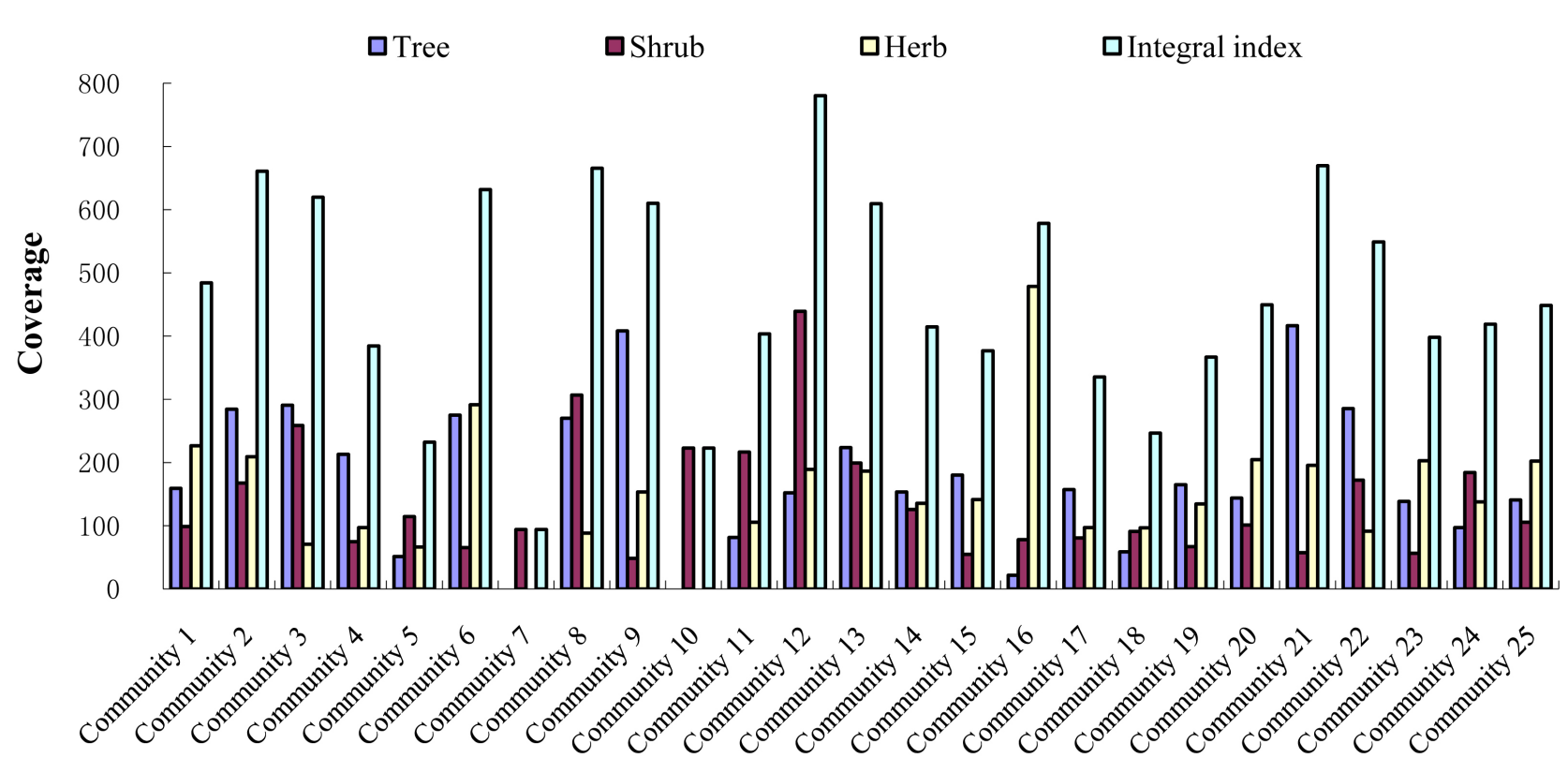

Figure 5. The coverage of every layer of 23 plant communities in Baguang region.

Seen from Figure 6, the average values of DBH of many communities were high, many were more than $30 \mathrm{~cm}$, and some were more than $60 \mathrm{~cm}$.

Seen the crown diameter of all trees in 25 communities (see Figure 7), many were more than $6 \mathrm{~m}$, some reached $8 \mathrm{~m}$.

Such as the comprehensive statistic indices which calculated the values their important value was top 3 of 19 plant communities in Dananshan and Xiaonanshan Mountain areas see Figures 8-10.

Seen Figure 8, the height of community 1 to community 12 where the most of communities were natural forests, and few were semi-natural forests of Xiaonanshan mountain areas were higher than that of community 13 to community 19 of Dananshan mountain areas where almost of all were artificial forests or artificial influence forests.

The values of crown diameter in every community see Figure 10.

Seen from Figure 9 and Figure 10 can understand that DBH and crown diameter of most natural forests communities in Xiaonanshan were higher than that of Dananshan of artificial forests or artificial influence or disturbance forests, in community 1 , community 2 , community 6 , community 7 , community 9 and community 10 of Xiaonanshan, their crown diameter values were obviously higher than that of Dananshan, some crown diameter values of Dananshan were higher than that of Xiaonanshan, but, in integral situation, the crown diameter values of about $70 \%$ communities which basic were natural forest in Xiaonanshan were higher than that of artificial forests of Dananshan.

Seen from the several Figures, in Xiaonanshan which most is natural forest, not only the values of height, $\mathrm{DBH}$ and crown diameter of trees of 3 dominant species were more high than that of Dananshan which major were artificial forests (although 1 to 2 artificial forests breeds, such as eucalyptus breed, its height of 


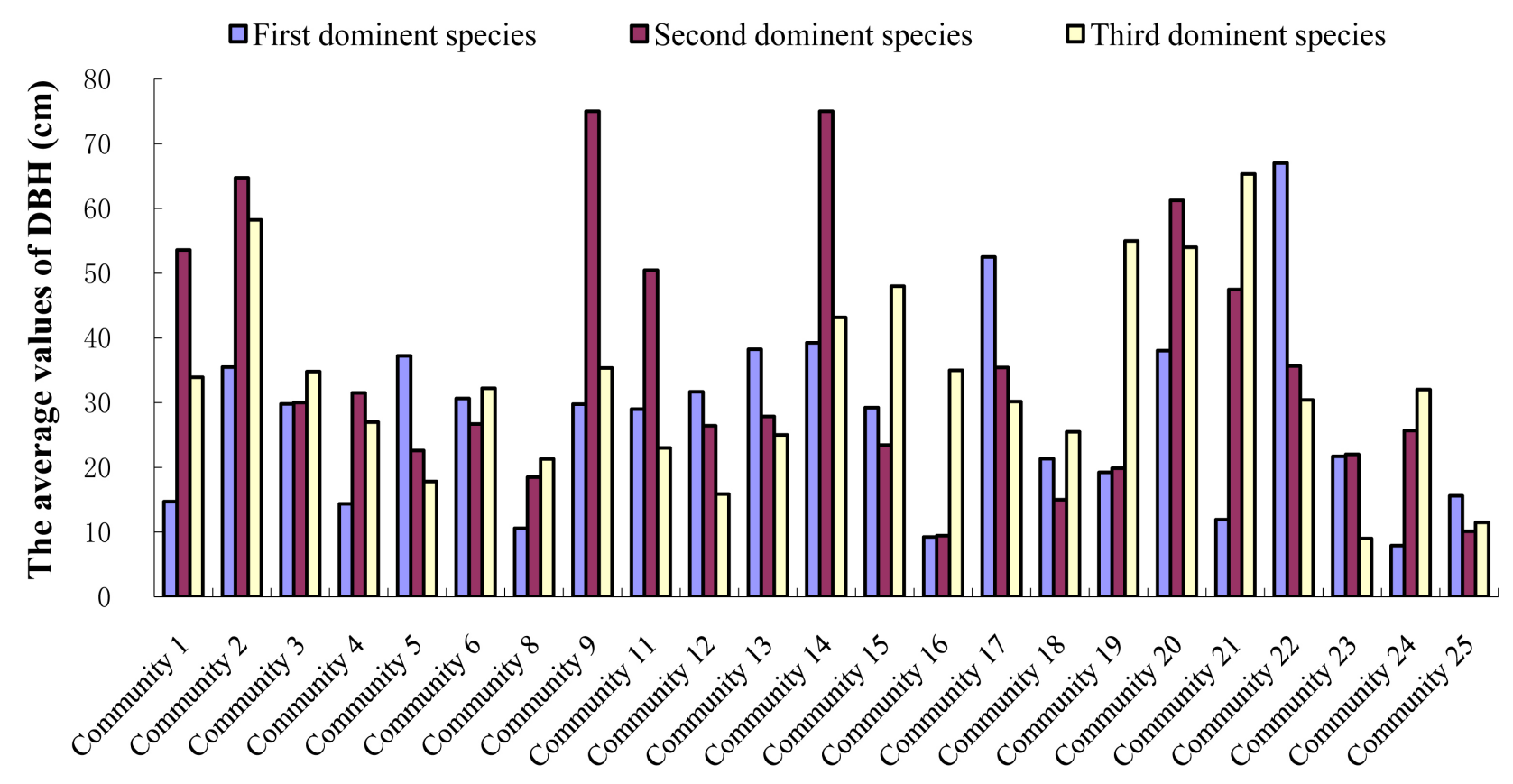

Figure 6. The average values of $\mathrm{DBH}$ of the first to throd dominent species 23 communities in Baguang region.

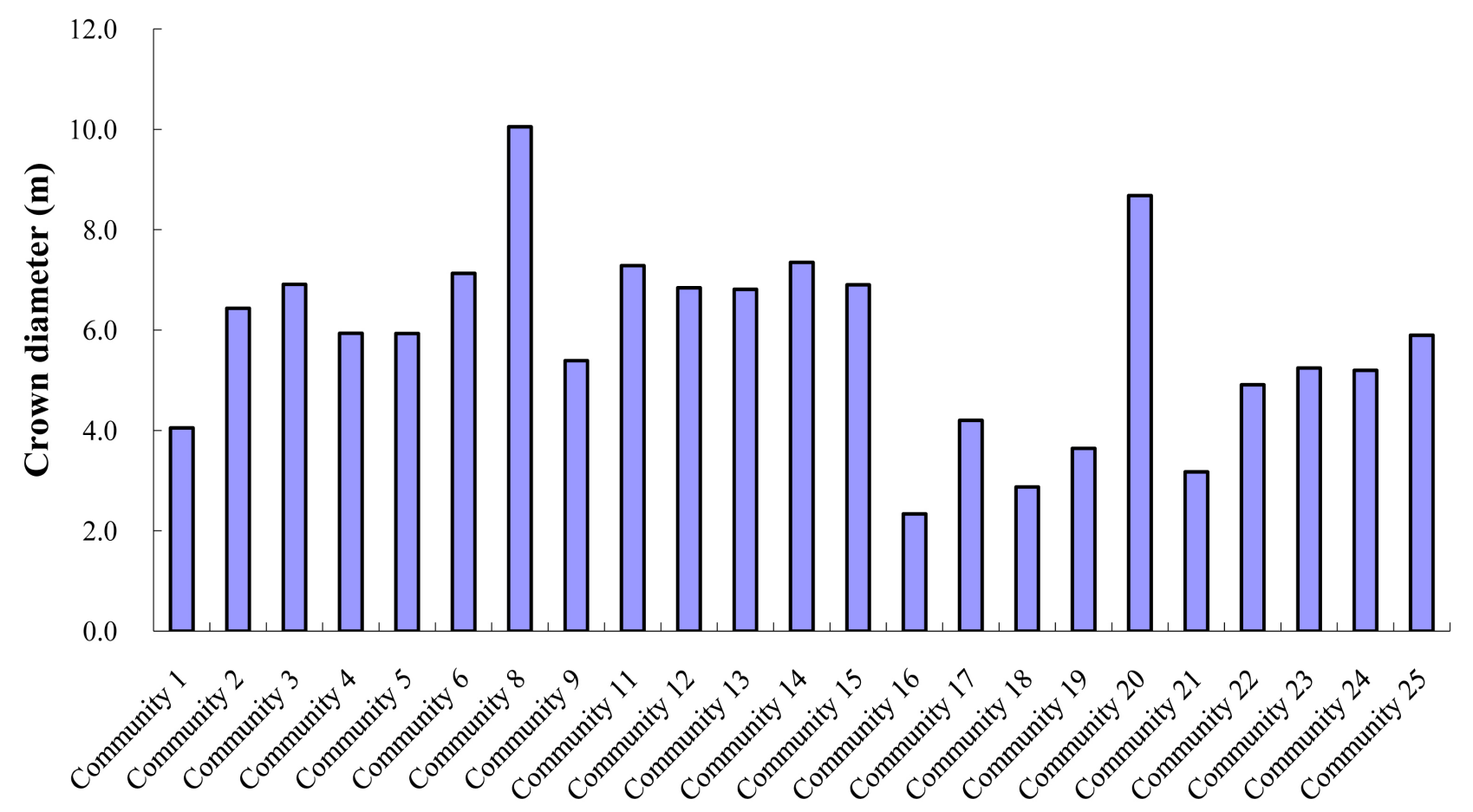

Figure 7. The values of average crown diameter of tree in all communities in Baguang region.

tree is higher), but also these indices of other non-dominant species of tree layer were higher than the latter too, showed that the growth of all tree species were more uniform, thus these communities can formed better or best structural system of community.

The coverage situation of different layer sees Figure 11. 


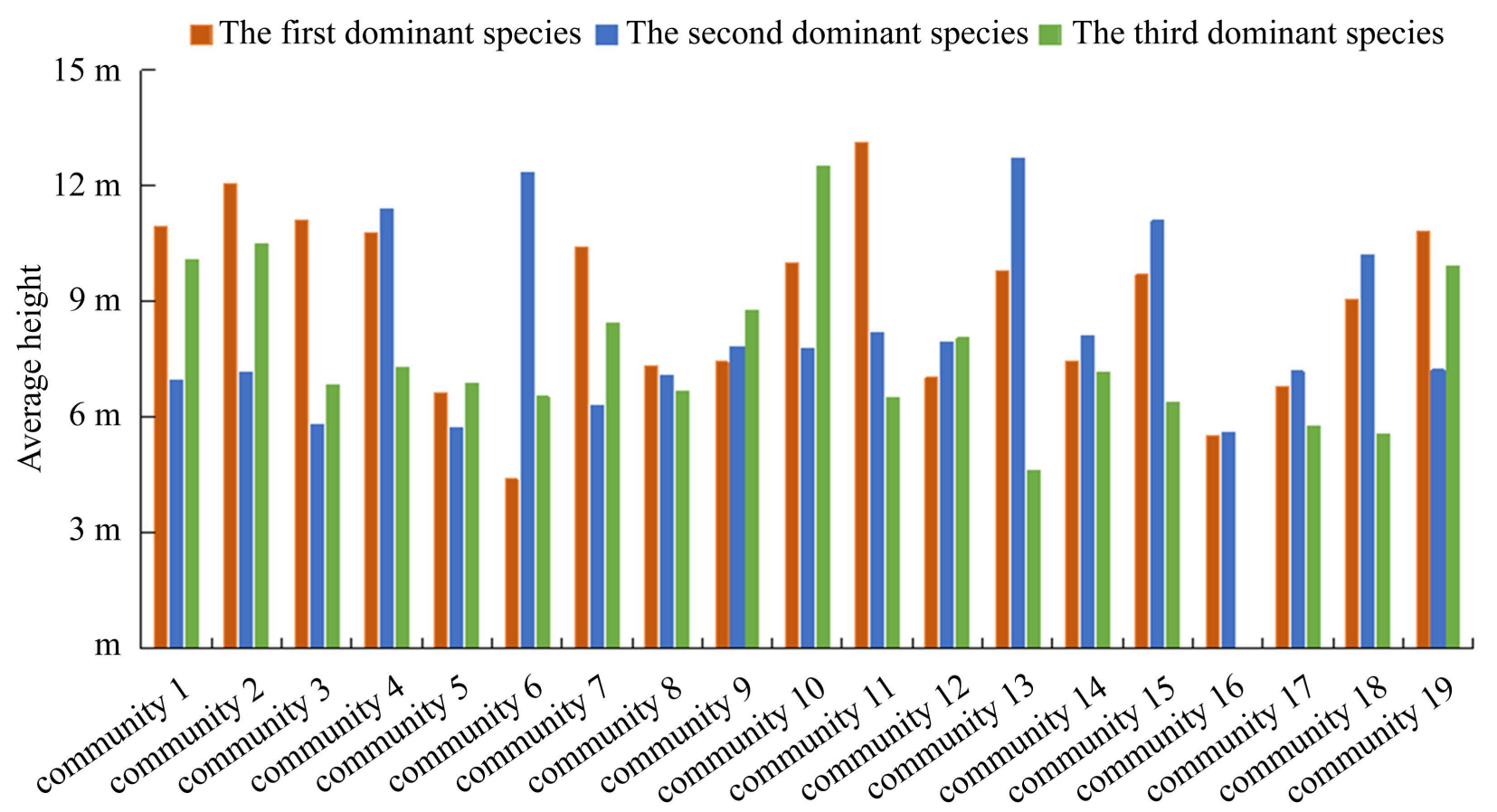

Figure 8. The average height of dominant species and major species in 19 plant communities of Dananshan and Xiaonanshan. Notes: Community 1 to Community 12 are the communities of Xiaonanshan mountain, community 13 to Community 19 are the communities of Dananshan mountain.

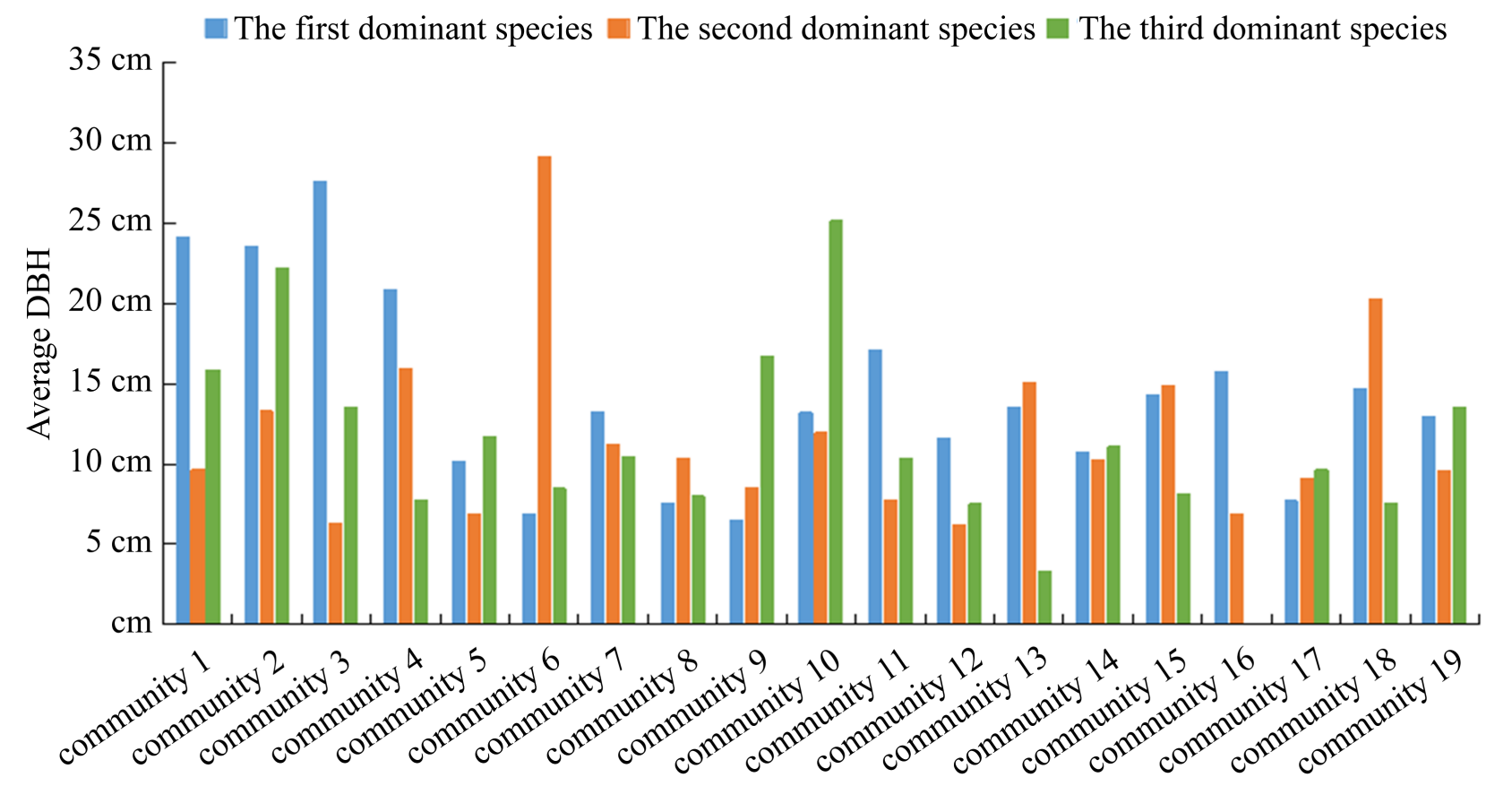

Figure 9. The average DBH of dominant species and major species in 19 plant communities of Dananshan and Xiaonanshan.

Seen Figure 11 can understand, in more than $90 \%$ communities, the coverage values of all layer were more than $300 \%$, some of them even surpassed $600 \%$. These showed that communities of Xiaonanshan and Dananshan mountain area were dense, in the communities, there existed more laminations. 


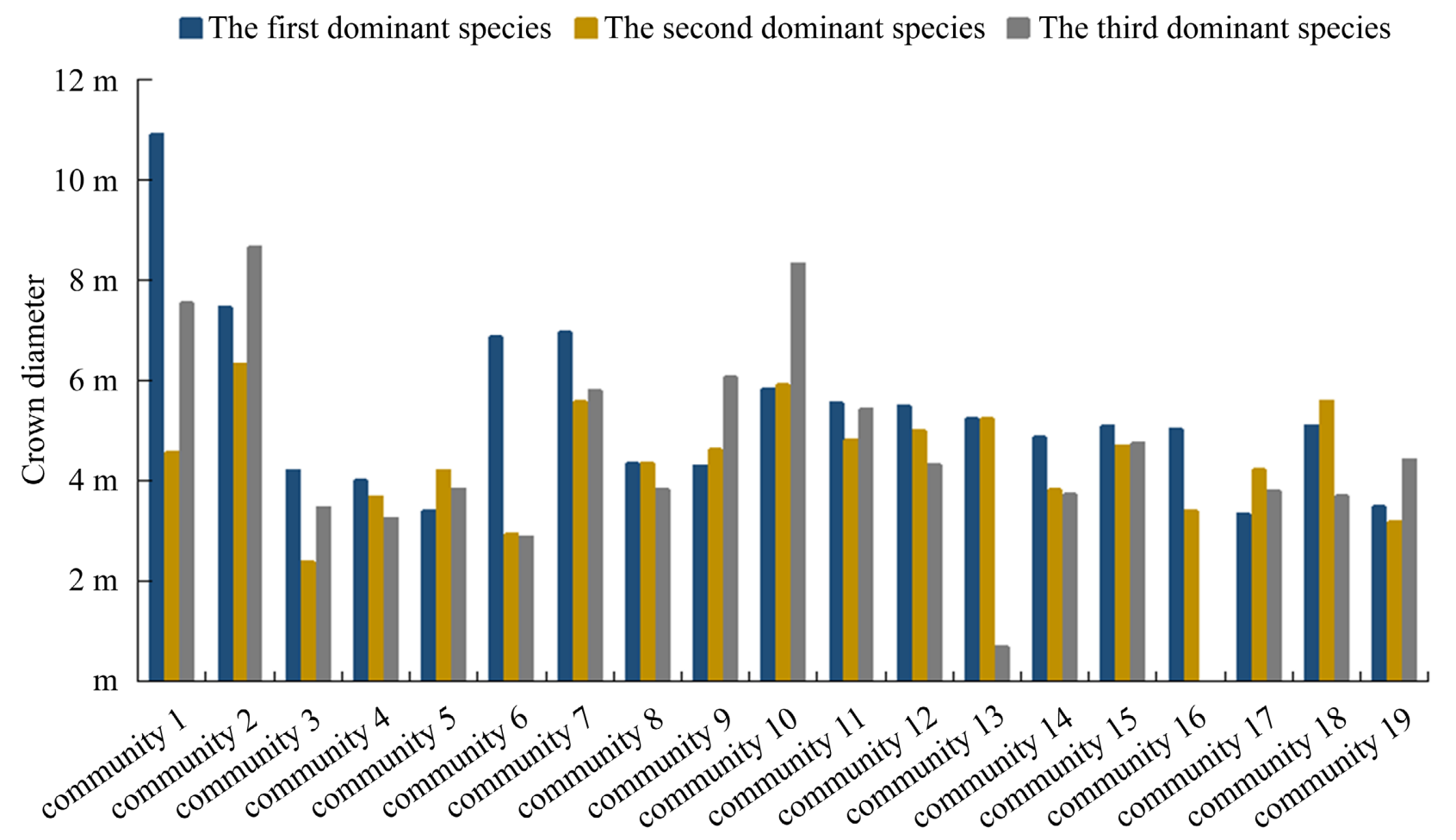

Figure 10. The crown diameter of dominant species and major species in 19 plant communities of Dananshan and Xiaonanshan.

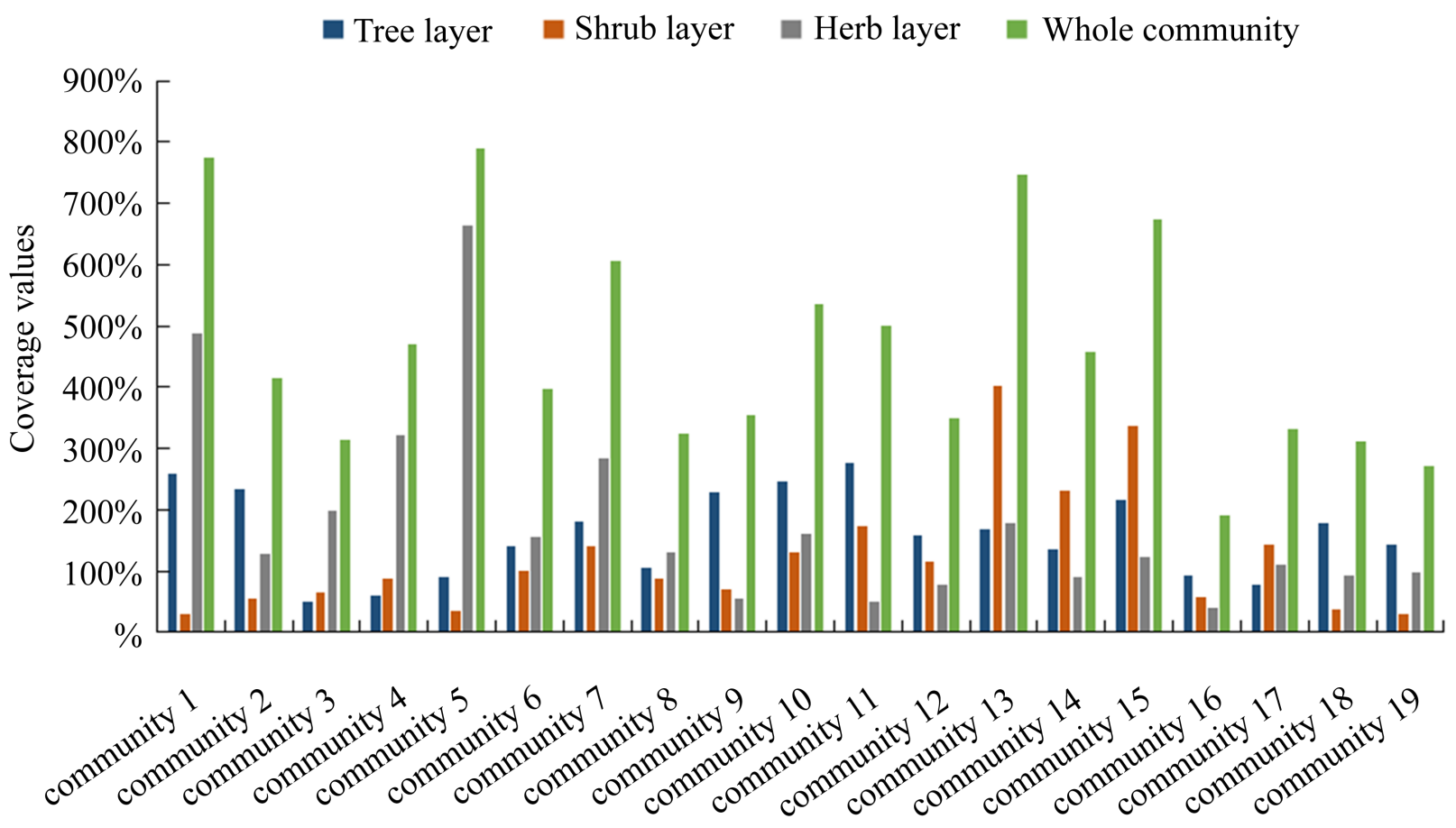

Figure 11. The coverage values of every layer of 19 communities in Dananshan and Xiaonanshan.

\subsection{The Quadrat Area Comparative Research Situation}

In 170 plant communities of our research, the quadrat area of every community were more than $600-2000 \mathrm{~m}^{2}$, few reached $3500-7600 \mathrm{~m}^{2}$ as comparative re- 
search, one reached $17,500 \mathrm{~m}^{2}$, these research results showed that used the random investigated method setting quadrat, combined typical investigated method that is set $600 \mathrm{~m}^{2}, 700 \mathrm{~m}^{2}, 800 \mathrm{~m}^{2}$, or $1200 \mathrm{~m}^{2}$ could investigated and understood number of all species in any community are without any difference, the species number of a community is not increase along with the quadrat area increase.

In the way, the research results main showed that these indices values are not higher when a total quadrat area of community is bigger than that of another community, or when the quadrat area is bigger or increase $100 \mathrm{~m}^{2}, 300 \mathrm{~m}^{2}$ or $1000 \mathrm{~m}^{2}$, its above all indices of community structure and diversity etc. shall not rise. In our researches process, using method of random investigated method setting quadrat, as long as then the quadrat area reached $600 \mathrm{~m}^{2}$ (it is the smallest quadrat area in our researches), it can satisfied the demand that can investigated all species and their characteristics; with the quadrat area increase, the species number of the community is not increase again. Even if the area increase to $2000 \mathrm{~m}^{2}, 2500 \mathrm{~m}^{2} 4600 \mathrm{~m}^{2}$ or over $4800 \mathrm{~m}^{2}$, the species number is still not increase, and the latter' species number in some communities are probably less than that of the community of smaller quadrat area, such as those quadrat area are $600 \mathrm{~m}^{2}$ or $700 \mathrm{~m}^{2}$.

Especially comparative with $600 \mathrm{~m}^{2}$ or $800 \mathrm{~m}^{2}$ with $3500 \mathrm{~m}^{2}, 4800 \mathrm{~m}^{2}$, or 7600 $\mathrm{m}^{2}$ in different community, the former species number are not less than that of the latter, their number is same or near, and usually the species number of the community which set $600 \mathrm{~m}^{2}, 800 \mathrm{~m}^{2}$ quadrat area are more than which communities set $3200 \mathrm{~m}^{2}, 4800 \mathrm{~m}^{2}$ even $17,500 \mathrm{~m}^{2}$ quadrat area.

Thereby, the height, coverage, $\mathrm{DBH}$, crow width etc. indices and all diversity indices of tree, shrub and herb layers of species and the integral values of family, genus and species are similar, or usually these indices in the community which set $600 \mathrm{~m}^{2}, 800 \mathrm{~m}^{2}$ quatrat are higher than that of $3000 \mathrm{~m}^{2}, 4000 \mathrm{~m}^{2}$ or $7000 \mathrm{~m}^{2}$ and 17,000 $\mathrm{m}^{2}$ quadrat area of community (Huang et al., 2016a; Huang et al., 2016b; Liang et al., 2016; Huang et al., 2020).

\subsection{The Study on Plant Diversity of Community}

The all communities were carried out research on diversity, richness and evenness indices and the similarity coefficient.

The first, each research region was made the comprehensive quantitative analysis, such as the situation of family, genus and species of every community in Nanshan region see Table 4, among 12 communities are the communities of Xiaonanshan Mountain, 3 communities are the communities of Dananshan Mountain.

There were 119 families, 300 genera and 447 species, tree layer was 53 families, 101 genera and 137 species, shrub layer was 46 families, 97 genera and 139 species, herb layer was 45 families, 96 genera and 125 species, liana was 46 species.

The number of family, genus, the number of species of every layer in each community were made analysis, the number comparative situation of species of 
Table 4. The number of family, genus and species of 15 plant communities of mountain areas of Nanshan region.

\begin{tabular}{cccc}
\hline Layer & Family & Genus & Species \\
\hline Tree & 53 & 101 & 137 \\
Shrub & 46 & 97 & 139 \\
Herb & 45 & 96 & 125 \\
Liana & 28 & 37 & 46 \\
\hline
\end{tabular}

every layer of 5 plant communities in Yangmeikeng mountain and Chiao area (Liang et al., 2016) see Figure 12.

Seen from Figure 12, in two places, the number of family of communities 1 of Yangmeikeng were less 1 family than that of community 5, and less 9 families than that of community 4 of Chiao, but community 3 was higher than the latter's. Number of genus of community 1 was lower than that of community 4 . In other two communities, community 2 was less in 1 genus than that of community 4, but its number of genus exceeded 10 genera than community 5 . Community 3 all values were higher than community 4 and community 5 .

\section{$a$-diversity index}

The plant diversity of mountain areas plant communities of Yangmeikeng and Chiao (Liang et al., 2016) see Table 5.

Seen from Figure 5, the number of tree species of communities 1, 2 and 3 in Yangmeikeng were apparently higher than two communities' in Chiao, the number of community 1 was 2 times of community 5 , and was 1.66 times of community 4; community 2 and 3 was respectively over 2 times of communities 4 and 5, the community 2 was almost 3 times than community 5 . In aspect of shrub species number, it was also showed the advantage of Yangmeikeng communities, even if the community 1 which the species number was fewer, was only less 1 species than that of community 5; and community 2 was higher than community 5, community 3 higher than communities 4 and 5 . Seen community 4 , the number of species reached 19 , although lower than community 3 , but it is higher than communities 1, 2. Seen the two communities of Chiao, the most species of community were shrub and herb, tree species number and its proportion were distinct low, indicated that in the man-made interference community, shrub and herb shall be the main components. Therefore compare natural or semi-natural forest with artificial forest diversity, not only see the diversity index, but also should analyse the layer of species proportion and composition.

We made also analysis on the diversity indices of family, genus of every community of the Lianhuashan Moutain, see Table 6.

Community 5 was the more artificial disturbed forest, its $D_{f}$ and $D_{g}$ was a little higher than community 1 , community 3 and community 4 , but its $D_{\mathrm{c}}$ was obvious lower than other three communities, in aspect of family richness $R_{R}, R_{f 2}$ of community 5 was lower than community 1 , community 2 and community 3 , only was higher than community 4 ; genus richness of community 5 was lower than all other communities. 


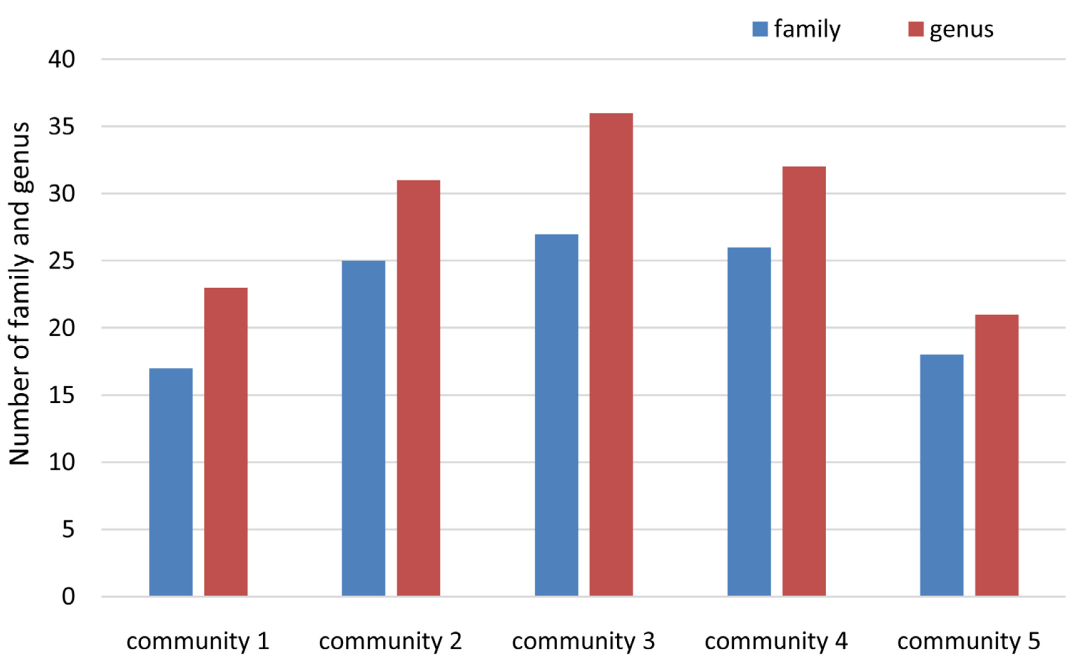

Figure 12. The number of family, genus $\left(R_{f}, R_{g 1}\right)$ in Yangmeikeng and Chiao, comm. 1 to comm. 3 are the comm. of Yangmeikeng, comm. 4 to 5 are the comm. of Chiao.

Table 5. The ecological indices of every layer of species diversity in Yangmiekeng and Chiao moutain areas.

\begin{tabular}{|c|c|c|c|c|c|c|}
\hline Plant communities & Layer & $D_{s}$ & $H$ & $J$ & $R_{1}$ & $R_{2}$ \\
\hline \multicolumn{7}{|l|}{ Yangmeikeng } \\
\hline \multirow{4}{*}{ Community 1} & Tree layer & 0.7906 & 1.7943 & 0.7793 & 2.1673 & 0.4992 \\
\hline & Shrub layer & 0.8033 & 1.7994 & 0.8189 & 2.3376 & in 0.5713 \\
\hline & Herb layer & 0.8332 & 1.6305 & 0.9100 & 2.1638 & 0.6457 \\
\hline & Integral value & 0.9037 & 2.6626 & 0.8272 & 4.7057 & 0.6234 \\
\hline \multirow{4}{*}{ Community 2} & Tree layer & 0.8774 & 2.2766 & 0.8976 & 3.0474 & 0.5743 \\
\hline & Shrub layer & 0.8667 & 2.1084 & 0.8427 & 2.7582 & 0.6012 \\
\hline & Herb layer & 0.8703 & 1.9827 & 0.8792 & 2.9118 & 0.7108 \\
\hline & Integral value & 0.9792 & 3.1334 & 0.9000 & 6.5832 & 0.6822 \\
\hline \multirow{4}{*}{ Community 3} & Tree layer & 0.8908 & 2.3022 & 0.8627 & 4.6873 & 0.5872 \\
\hline & Shrub layer & 0.8908 & 2.5657 & 0.8793 & 4.6332 & 0.6724 \\
\hline & Herb layer & 0.7967 & 1.7108 & 0.9024 & 2.0791 & 0.5783 \\
\hline & Integral value & 0.9565 & 3.3424 & 0.8886 & 7.7312 & 0.7001 \\
\hline \multicolumn{7}{|l|}{ Chiao } \\
\hline \multirow{4}{*}{ Community 4} & Tree layer & 0.3685 & 0.6307 & 0.3520 & 1.0453 & 0.3126 \\
\hline & Shrub layer & 0.8737 & 1.5343 & 0.4964 & 3.8329 & 0.5385 \\
\hline & Herb layer & 0.9053 & 0.7937 & 0.3194 & 2.0907 & 0.4329 \\
\hline & Integral value & 0.9028 & 2.9584 & 0.8020 & 6.9689 & 0.6427 \\
\hline \multirow{4}{*}{ Community 5} & Tree layer & 0.4555 & 0.6467 & 0.4018 & 0.9889 & 0.3183 \\
\hline & Shrub layer & 0.7902 & 0.8125 & 0.3388 & 2.1756 & 0.4742 \\
\hline & Herb layer & 0.6746 & 0.9347 & 0.4495 & 1.5822 & 0.4113 \\
\hline & Integral value & 0.8734 & 2.3940 & 0.7533 & 4.7467 & 0.6285 \\
\hline
\end{tabular}


Table 6. The indices of diversity, richness and composite diversity of family, genus in every community, Lianhuashan Mountain.

\begin{tabular}{cccccccc}
\hline Communities & $D_{f}$ & $D_{g}$ & $D_{\mathrm{c}}$ & $R_{\mathrm{f}}$ & $R_{f}$ & $R_{g 1}$ & $R_{g 2}$ \\
\hline 1 & 0.9323 & 0.9758 & 2.8278 & 26 & 7.5020 & 32 & 8.6747 \\
2 & 0.9411 & 0.9970 & 2.8643 & 29 & 8.0312 & 37 & 10.0302 \\
3 & 0.9423 & 0.9905 & 2.8827 & 24 & 6.8639 & 33 & 9.1390 \\
4 & 0.9286 & 0.9852 & 2.8689 & 21 & 6.2365 & 29 & 8.2238 \\
5 & 0.9441 & 0.9967 & 2.8455 & 22 & 6.9225 & 24 & 7.4562 \\
\hline
\end{tabular}

Seen from Table 7, the diversity values order of tree layer were that community $1>$ community $3>$ community $7>$ community $10>$ community $2>$ community $6>$ community $9>$ community $17>$ community $12>$ community $11>$ community $8>$ community $15>$ community $4>$ community $5>$ community $19>$ community $18>$ community $13>$ community $14>$ community 16 . In the comprehensive situation, the plant diversity of natural forests of Xiaonanshan mountain areas was higher than that of Dananshan mountain areas where were major artificial forests.

In the respect of shrub and herb layer, the situation of diversity were similar to tree layer, the values were fewer difference between two regional mountain areas.

The richness indices of species of every layer in 19 communities of Nanshan region see Table 8.

The richness indices of tree layer of Xiaonanshan natural forests were higher than that of Dananshan artificial forests.

The richness indices of shrub and herb layer between Xiaonanshan and Dananshan were near.

We thought that if the community possessed most tree species, and more shrub species and herb species, its development and structure are better or is best community; if the community only is shrub, even herb plant species occupied most of proportion, even if its species diversity is also same height, or surpass some number than the former, but it is a damaged rather more and structure is loss, it is a community of restoration process (the region is the condition there' clime environment can allow development to trees), so when we analyze the community structure and diversity, not only need analysis the diversity indices values, but also need combine analysis the composition of species in the biological characteristics, such as the proportion of species and their individual of tree, shrub and herb, and indices of their height, coverage etc., and the ecological benefits to local region, then analyze and commented its character which what stage of succession it is and the structural level of community.

\section{$B$-diversity}

About 35\% communities were carried out similarity coefficient of family, genus and synthetic similarity coefficient calculated, $85 \%$ communities were carried out species similarity coefficient calculated in every large region. Such as the analysis of similarity coefficient of species in communities of Yangmeikeng mountain areas with Chiao areas (Liang et al., 2016) see Table 9. 
Table 7. The species diversity indices of every plant community in Dananshan and Xiaonanshan mountain areas.

\begin{tabular}{|c|c|c|c|c|c|c|}
\hline \multirow{2}{*}{$\begin{array}{l}\text { Community } \\
\text { Order }\end{array}$} & \multicolumn{2}{|c|}{ Arbor Layer } & \multicolumn{2}{|c|}{ Shrub Layer } & \multicolumn{2}{|c|}{ Herb Layer } \\
\hline & $D$ & $H$ & $D$ & $H$ & $D$ & $H$ \\
\hline 1 & 0.9228 & 2.7598 & 0.8248 & 2.2709 & 0.6714 & 1.7336 \\
\hline 2 & 0.8941 & 2.4002 & 0.8423 & 2.3678 & 0.6488 & 1.3416 \\
\hline 3 & 0.9249 & 2.6616 & 0.9055 & 2.6876 & 0.6077 & 1.3103 \\
\hline 4 & 0.8204 & 2.0081 & 0.9204 & 2.8261 & 0.8033 & 1.9118 \\
\hline 5 & 0.8013 & 1.6459 & 0.8742 & 2.3839 & 0.5357 & 0.9904 \\
\hline 6 & 0.8923 & 2.3910 & 0.8529 & 2.1334 & 0.8182 & 2.2993 \\
\hline 7 & 0.9167 & 2.5452 & 0.8538 & 2.5618 & 0.8105 & 1.9169 \\
\hline 8 & 0.8493 & 2.1791 & 0.8367 & 2.3277 & 0.7280 & 1.5246 \\
\hline 9 & 0.8645 & 2.3617 & 0.8651 & 2.4044 & 0.6386 & 1.2747 \\
\hline 10 & 0.8669 & 2.4189 & 0.9261 & 2.8559 & 0.8712 & 2.3671 \\
\hline 11 & 0.8405 & 2.2393 & 0.9271 & 2.9339 & 0.8246 & 2.1564 \\
\hline 12 & 0.8638 & 2.2466 & 0.8718 & 2.5584 & 0.8278 & 0.0518 \\
\hline 13 & 0.6628 & 1.3177 & 0.7761 & 1.8984 & 0.6457 & 1.6470 \\
\hline 14 & 0.6317 & 1.2742 & 0.8326 & 2.0828 & 0.9944 & 0.4991 \\
\hline 15 & 0.7966 & 2.0261 & 0.9170 & 2.9404 & 0.3542 & 0.9231 \\
\hline 16 & 0.0998 & 0.2036 & 0.8887 & 2.5067 & 0.4524 & 1.2095 \\
\hline 17 & 0.8562 & 2.2902 & 0.9432 & 3.0581 & 0.7608 & 1.8455 \\
\hline 18 & 0.6667 & 1.4506 & 0.9060 & 2.7321 & 0.6246 & 1.2492 \\
\hline 19 & 0.7395 & 1.4658 & 0.8278 & 2.2453 & 0.7991 & 1.8729 \\
\hline
\end{tabular}

Notes: $D$ is Simpson index; $H$ is Shannon-Wiener index; the community 1 to community 12 were the communities of Xiaonanshan, community 13 to community 19 were the communities of Dananshan.

Table 8. The species richness of 19 communities in Dananshan and Xiaonanshan.

\begin{tabular}{cccc}
\hline \multirow{2}{*}{ Community order } & \multicolumn{3}{c}{ R (Odum index) } \\
\cline { 2 - 4 } 1 & Arbor Layer & Shrub Layer & Herb Layer \\
\hline 2 & 4.8200 & 4.5147 & 3.0685 \\
3 & 3.2863 & 4.8283 & 1.6647 \\
4 & 4.4427 & 5.0822 & 2.0065 \\
5 & 3.0018 & 5.2592 & 2.8854 \\
6 & 1.4482 & 3.6897 & 1.2706 \\
7 & 3.0086 & 2.9800 & 3.0807 \\
8 & 3.9436 & 5.1116 & 2.5131 \\
9 & 3.6308 & 4.2752 & 1.7012 \\
10 & 3.9810 & 4.1966 & 2.3175 \\
\hline
\end{tabular}




\section{Continued}

\begin{tabular}{llll}
\hline 11 & 3.6510 & 6.0039 & 3.6139 \\
12 & 3.4975 & 4.5433 & 2.7013 \\
13 & 1.6891 & 3.4437 & 2.6948 \\
14 & 1.4950 & 2.8695 & 1.5537 \\
15 & 2.5461 & 6.6609 & 2.0344 \\
16 & 0.4926 & 4.3621 & 3.2868 \\
17 & 3.5470 & 6.3770 & 2.4628 \\
18 & 1.8309 & 5.3399 & 1.6700 \\
19 & 1.3470 & 4.2150 & 2.6291 \\
\hline
\end{tabular}

Table 9. The similarity coefficient of species of communities of Yangmeikeng and Chiao mountain areas.

\begin{tabular}{cccccc}
\hline $\begin{array}{c}\text { Name of } \\
\text { community }\end{array}$ & Community 1 & Community 2 & Community 3 & Community 4 & Community 5 \\
\hline Community 1 & 1.0000 & & & & \\
Community 2 & 0.2857 & 1.0000 & & & \\
Community 3 & 0.2903 & 0.4722 & 1.0000 & & \\
Community 4 & 0.2712 & 0.2319 & 0.7333 & 1.0000 & 1.0000 \\
Community 5 & 0.1333 & 0.1454 & 0.3607 & 0.4482 & \\
\hline
\end{tabular}

Notes: Comm. 1 to Comm. 3 are the communities of Yangmeikeng, Comm. 4 and Comm. 5 are the communities of Chiao.

Such as the analysis of similarity coefficient of species in communities of Dananshan and Xiaonanshan mountain areas see Table 10.

Seen the similarity coefficient values, most of communities composition of species each other were more different, the values were middle or lower, about values of $65 \%$ - $75 \%$ were lower, showed that in a wide scope, the plant diversity were higher in Shenzhen.

Synthetical similarity coefficient of family, genus and species in Yangmeikeng and Chiao mountain areas see Table 11.

Seen from Table 11, although incorporated family and genus genetic factors, but the most of index values of communities were lower, especially between community 1 , community 2 with community 5 . These showed that the difference of community composition is larger in two regions, even if the differences of every community composition in same region are also quite more; identified that the plant diversity in this large region is higher.

\subsection{Measured and Analyzed the Plant Community's Ability of Absorbed and Reduced $\mathbf{P M}_{2.5}$}

We carried out the measured researches on the relationship of structure characteristics of plant communities with the ability of absorbed and reduced $\mathrm{PM}_{2.5}$ pollutants in 21 plant communities of 4 Districts, Shenzhen. 
Table 10. The similarity coefficient of species of communities of Dananshan and Xiaonanshan mountain areas.

\begin{tabular}{|c|c|c|c|c|c|c|c|c|c|c|c|c|c|c|c|c|c|c|c|}
\hline $\begin{array}{l}\text { No. of } \\
\text { Co-mm. }\end{array}$ & 1 & 2 & 3 & 4 & 5 & 6 & 7 & 8 & 9 & 10 & 11 & 12 & 13 & 14 & 15 & 16 & 17 & 18 & 19 \\
\hline 1 & 1.0000 & & & & & & & & & & & & & & & & & & \\
\hline 2 & 0.5667 & 1.0000 & & & & & & & & & & & & & & & & & \\
\hline 3 & 0.5827 & 0.6306 & 1.0000 & & & & & & & & & & & & & & & & \\
\hline 4 & 0.4892 & 0.5366 & 0.5692 & 1.0000 & & & & & & & & & & & & & & & \\
\hline 5 & 0.3363 & 0.3505 & 0.4615 & 0.4655 & 1.0000 & & & & & & & & & & & & & & \\
\hline 6 & 0.1833 & 0.1731 & 0.1441 & 0.2276 & 0.1237 & 1.0000 & & & & & & & & & & & & & \\
\hline 7 & 0.5581 & 0.4956 & 0.5167 & 0.5303 & 0.3396 & 0.1770 & 1.0000 & & & & & & & & & & & & \\
\hline 8 & 0.5042 & 0.4466 & 0.4727 & 0.5246 & 0.3542 & 0.1553 & 0.6071 & 1.0000 & & & & & & & & & & & \\
\hline 9 & 0.5210 & 0.5437 & 0.5091 & 0.4754 & 0.4167 & 0.1942 & 0.3929 & 0.43141 & 1.0000 & & & & & & & & & & \\
\hline 10 & 0.4672 & 0.4132 & 0.4219 & 0.4143 & 0.2982 & 0.1983 & 0.3846 & 0.43330 & 0.4667 & 1.0000 & & & & & & & & & \\
\hline 11 & 0.5303 & 0.3966 & 0.4390 & 0.4296 & 0.3486 & 0.1897 & 0.4320 & 0.52170 & 0.5043 & 0.5263 & 1.0000 & & & & & & & & \\
\hline 12 & 0.5041 & 0.3925 & 0.4386 & 0.4286 & 0.3400 & 0.1682 & 0.4655 & 0.50940 & 0.4528 & 0.4839 & 0.6218 & 1.0000 & & & & & & & \\
\hline 13 & 0.3186 & 0.2474 & 0.3269 & 0.3448 & 0.1556 & 0.1856 & 0.2830 & 0.29170 & 0.2708 & 0.3158 & 0.3119 & 0.3400 & 1.0000 & & & & & & \\
\hline 14 & 0.1837 & 0.1707 & 0.2697 & 0.2574 & 0.1333 & 0.1220 & 0.2198 & 0.19750 & 0.1975 & 0.2020 & 0.2340 & 0.2118 & 0.5600 & 1.0000 & & & & & \\
\hline 15 & 0.3200 & 0.3853 & 0.3966 & 0.3906 & 0.2941 & 0.1651 & 0.3559 & 0.40740 & 0.4259 & 0.4286 & 0.4132 & 0.4286 & 0.3333 & 0.29891 & 1.0000 & & & & \\
\hline 16 & 0.1333 & 0.1622 & 0.1975 & 0.1720 & 0.0896 & 0.0270 & 0.1446 & 0.16440 & 0.1918 & 0.1319 & 0.1860 & 0.1558 & 0.0597 & 0.15380 & 0.15191 & 1.0000 & & & \\
\hline 17 & 0.2500 & 0.2321 & 0.3193 & 0.3053 & 0.1905 & 0.2500 & 0.2149 & 0.27030 & 0.3243 & 0.2791 & 0.3548 & 0.2783 & 0.4571 & 0.35560 & 0.44440 & 0.2195 & 1.0000 & & \\
\hline 18 & 0.2202 & 0.2151 & 0.2000 & 0.2321 & 0.0930 & 0.1075 & 0.1961 & 0.17390 & 0.2174 & 0.2182 & 0.2286 & 0.2500 & 0.3488 & 0.45070 & 0.24490 & 0.1270 & 0.33661 & 1.0000 & \\
\hline 19 & 0.2667 & 0.2472 & 0.2708 & 0.3148 & 0.1463 & 0.1348 & 0.2245 & 0.25000 & 0.2273 & 0.2642 & 0.2970 & 0.2609 & $0.3902 \mathrm{c}$ & 0.47760 & 0.34040 & 0.2373 & 0.32990 & 0.5385 & 1.0000 \\
\hline
\end{tabular}

Notes: Comm. 1 to Comm.12 are the communities of Xiaonanshan, Comm. 13 to Comm. 19 are the communities of Dananshan.

Table 11. Synthetical similarity coefficient $\left(\beta_{c}\right)$ of family, genus and species in Yangmeikeng and Chiao moutain areas.

\begin{tabular}{cccccc}
\hline Community & 1 & 2 & 3 & 4 & 5 \\
\hline 1 & 1.0000 & & & & \\
2 & 0.3474 & 1.0000 & & & \\
3 & 0.3146 & 0.4633 & 1.0000 & & \\
4 & 0.3037 & 0.3296 & 0.4490 & 1.000 & \\
5 & 0.1920 & 0.2250 & 0.4171 & 0.5841 & 1.000 \\
\hline
\end{tabular}

Notice: 1 to 3 is the communtiy of Yangmeikeng mountain area, 4 to 5 is the community of Chiao moutain area.

The result showed that in the 21 plant communities, in $25 \%$ communities, $\mathrm{PM}_{2.5}$ concentrations of forest inside were $6-15 \mu \mathrm{g} / \mathrm{m}^{3}$ lower than that of outside of forests, in about $45 \%$ communities, their $\mathrm{PM}_{2.5}$ concentration of forest inside were $20-25 \mu \mathrm{g} / \mathrm{m}^{3}$ lower than that of outside of forests, about $15 \%$ communities reducing $\mathrm{PM}_{2.5}$ more than $30 \mu \mathrm{g} / \mathrm{m}^{3}, 15 \%$ communities reducing $\mathrm{PM}_{2.5}$ reached $40-46 \mu \mathrm{g} / \mathrm{m}^{3}$. 
In the aspect of reducing $\mathrm{PM}_{2.5}$ concentration value, between the sites where were different distance to forest inside with the reducing $\mathrm{PM}_{2.5}$ quantity were without regular, showed that different sites where were $1 \mathrm{~m}, 4 \mathrm{~m}$ and $8 \mathrm{~m}$ from outside to inside of forests all absorbing and reducing $\mathrm{PM}_{2.5}$ effect were near, these result showed that forest is not like that because of the longer distance to the forest outside (there the $\mathrm{PM}_{2.5}$ pollutants are more than inside of forest) where shall be more restarted $\mathrm{PM}_{2.5}$ by branches and leave, so that the concentration shall lower than that of branch and leave site of forest edge, these indicated that plant community is meantime absorbing $\mathrm{PM}_{2.5}$ pollutant with same quantity in unit time by means of every place, so, in a region, when the plant community area is more, its integral absorbing $\mathrm{PM}_{2.5}$ quantity shall be more.

The relationship the comprehensive indices such as the height, coverage, density etc. of community with absorbed $\mathrm{PM}_{2.5}$ ability were a positive correlation, showed that the better structure of plant community are, the stronger their absorbed ability to $\mathrm{PM}_{2.5}$ are.

The $\mathrm{PM}_{2.5}$ pollution treatment experiments in closed fumigated box were carried out to more plant species, in two hours, 2 numbers of plant, most of plant species absorbed amount of $\mathrm{PM}_{2.5}$ were $65-110 \mu \mathrm{g} / \mathrm{m}^{3}$, then 4 plants, most of plants absorbed $\mathrm{PM}_{2.5}$ amount were $90-130 \mu \mathrm{g} / \mathrm{m}^{3}$, then 10 plants, most of plants absorbed amount of $\mathrm{PM}_{2.5}$ reached $120-175 \mu \mathrm{g} / \mathrm{m}^{3}$; when the treatment time was extended, the absorbed amount to $\mathrm{PM}_{2.5}$ were obvious increase, after treatment 4 hours, the absorbed amount was near two times to that of 2 hours; showed that building and maintaining city good plant community structure is very important to purified air $\mathrm{PM}_{2.5}$ pollutant.

We yet investigated, collected binding and identified plant specimens and set up the figures and literal data base, total invested collected, binding and identified plant specimens 15,600 in above regions of Shenzhen and set up the figures and literal data base, so that can check the distribution of any species and resource, and make more researches in plant taxonomy, phytogeography and evolution, and supplied proofs for local vegetation system composition in further research.

\section{Discussion}

1) In aspect of plant community structure, Shenzhen, the order from better to weak is that natural forest $>$ semi-natural forest $>$ artificial forest or artificial disturbed forest; in most of natural forests or semi-natural forests, the indices of height, coverage, $\mathrm{DBH}$, crow width and density etc. in tree and shrub layer are higher than more other region, even some natural forests of other regions (Zhu et al., 2004; Burton et al., 2005); even these main indices of communities are higher than that of some natural forest of tropical region (Li et al., 2008). These showed that if made a good protection to vegetion, they shall obtain good growth and development, forming well and complex plant communties structure in the subtropical geographic environment (Huang et al., 2020). 
2) Above research results are better evidences and references to the argument problems on that is natural forest and natural restoration forest biodiversity higher? Or is artificial forest biodiversity higher? and or is more artificial disturbed forest higher? (Mao \& Zhu, 2006; Wang et al., 2013). These research results proved that the plant diversity of natural forest or long time natural restoration forest is obviously higher than artificial forest or more artificial disturbed forest (Huang et al., 2016a; Huang et al., 2016b; Liang et al., 2016).

3) Our research results showed that the height, coverage, $\mathrm{DBH}$, crown width etc. indices in the all layers of community and all diversity indices ( $\alpha$-diversity) of tree, shrub and herb layers and the integral values are similar, same or usually these indices in the community which set $600 \mathrm{~m}^{2}, 800 \mathrm{~m}^{2}$ total quadrat area were higher than that of $3000 \mathrm{~m}^{2}, 4000 \mathrm{~m}^{2}$ or $7000 \mathrm{~m}^{2}$, even more than $17,000 \mathrm{~m}^{2}$ total quadrat area of communities; using smaller total quadrat area or larger total quadrat area, they all can understand the actual characteristics and situation of community. These lots of researches further proved that according to minimum area method for vegetation survey, in subtropical region, using random investigation method combined with typical investigation set $400 \mathrm{~m}^{2}$ or $400 \mathrm{~m}^{2}-500$ $\mathrm{m}^{2}$ total quadrat area in a community is correct (Zhang, 2011), or $510-600 \mathrm{~m}^{2}$ quadrat is more stability to the investigation of plant community.

4) Compared the index values of plant diversity in Shenzhen with other some cities or some wild mountain areas, its plant diversity is higher, such as most of diversity indices were higher than that 4 communities of Lingnan Natural Conservation Area in Anhui Province (Li et al., 2007).

Xishuangbanna tropical rain forests region is one of the regions which plant communities structure are most complex, and their plant diversity are very plentiful, Li et al. (2004) studied 6 communities of tropical mountain rain forests in Xishuangbanna, compare with our researched index $D_{s}$, take Yangmeikeng and Chiao two regions as represent, the 3 communities' values of Yangmeikeng were all higher than the community 1 and community 2 of the former, but were lower than that of other 4 communities of the former, two communities' values of Chiao were obviously lower than all communities' of the former. It is further showed that the communities of Yangmeikeng which were conserved, their vegetation restoration were very well, so that the diversity were so high, and surpassed some communities of the tropical rain forest region of Xishuangbanna. And the negative effect of artificial disturbance to Chiao' communities were also reflected.

Wale et al. (2012) researched results which measured to 3 communities of Gonder, Amhara of Northern Ethiopia showed that their integral $H$ values all were at a rather high level in this national conservation region; yet take the Yangmeikeng and Chiao as represent regions, our researched integral $H$ values, the communities 2 and community 3 of Yangmeikeng were higher than that of the former, other values were lower than the former's. So even though the biodiversity of the regions which were protected in Shenzhen are higher, but they are still having rise space. 
5) Some indices of few artificial disturbed forest or artificial forest were a lightly higher, but the values were not obvious difference to natural forests; and this contribution major was herb layer plants and some shrub layer plants, but the integral values of the diversity indices of natural forest and semi-natural forest were obvious higher than the former. The research showed that in the artificial disturbed forest or artificial forest, because have some little scale clearing area, so some pioneer plant species could entered the community and formed a temporarily species diversity increase, however these species major are some shrub and herb plants; but tree layer possessed biomass is obvious more, even surpass several tens times than shrub and herb layers, therefore in the respect of maintain ecosystem stability and other ecological effect have major and dominated position and so on; and then this community can natural recovery and succession, those new entried above plants shall withdraw from the community and are replaced by the original plants of the community; but this process has already caused the ecological benefits loss and ecosystem unstable.

6) Seen the $\beta$-diversity indices of species, the species composition of communities between each region are more difference, specially the different natural forest communities are thus, the values of similarity coefficient of species of communities are very low or lower, but the values of artificial forest or people disturbed forest are higher, these proved that in a large region, if more artificial forest or people disturbed forest, the plant diversity of there are low or abvious low. In the comprehensive situation, between plant communities in different regions are more difference, therefore it constituted a higher plant diversity level in Shenzhen city.

7) Our investigation researches showed that the distribution pattern of vegetation in Shenzhen is that natural forest occupied a little proportion, it is about $17 \%$ proportion; semi-natural forest occupied about $15 \%$ proportion, about $68 \%-70 \%$ proportion of city area is artificial forestsin mountain area and parks etc., major species are Litchi chinensis, Ferocactus viridescens, Acacia auriculiformis, Acacia confusa, some breeds of Eucalyptus, few are Castanopsis fissa, Schima superba etc.

Thus, caused the situation that majority of vegetation communities structures are weak, and a few are bad, the plant diversity level of the places where are artificial forests are rather lower, although the integral diversity level of the city is higher, it is the contribution of natural forest and semi-natural forest. Therefore, in the region where the hydrothermal condition are so well, ought to implement the effective measures to reform most of mountain artificial forests, so that rise the plant community stability and further optimize the ecosystem, elevate its ecological benefits in absorbing carbon dioxide, purificating of atmospheric pollutants and conservation of both moisture and soil.

8) When analyzing a regional plant community biodiversity, if calculate only the species diversity, it shall understand only the species grade situation, so, if need understand the diversity situation of whole nenutic level, not only calculate species diversity, but also need calculate the diversity of family, genus, and need 
analysis combining the indices of diversity, evenness and richness of several grades of family, genus and species, and combining the component situation of every layer of community, it shall can obtain more objective and roundly evaluation.

Made the calculateIn on $\beta$-diversity of family, genus and species can better compare the difference of each genetic level of plant between each community. In aspect of synthetical similarity coefficient $\left(\beta_{c}\right)$ of family, genus and species, it reflected basic aforementioned the 3 grades difference situation in between each community, can reflected a large region plant diversity situation.

9) Our investigation researches showed that several alien invasive herb species, such as Mikania micrantha, the method which spray insecticide or cut them with local native species are error, thus methods not only cannot clean out the invasive species, but also seriously damaged local plant composition and diversity. The most effective prevention and control method is that let local plants have a good growth environment and condition, let they have a good competitive power to the alien invasive species. Our observed showed that than the local plant growth were well in the condition with without peoples disturbed, the forest was dense, the alien invasive species were not can or very few entry the community, they were in the weak prospect or complete without any number in these places. Thus, it achieved protected local well vegetation aim, meanwhile control and reduced invasive alien species.

10) Our researches proved that plant community has a good absorbed $\mathrm{PM}_{2.5}$ capability, therefore reduce $\mathrm{PM}_{2.5}$ concentration in atmosphere. In former times, almost of researcher thought that plant can only block $\mathrm{PM}_{2.5}$ pollutants rely on the surface of leaf, and not understand they wether can or don't think they can absorb $\mathrm{PM}_{2.5}$ (Ji et al., 2013; Chen et al., 2014; Zhao et al., 2016). The better community structure is, the stronger its absorbed and reduced $\mathrm{PM}_{2.5}$ ability is. Their reduced $\mathrm{PM}_{2.5}$ capability in different plant communities were scope in 20 $50 \mu \mathrm{m} / \mathrm{m}^{3}$ than outside of forest in instantaneous measurement; the better community structure possessed stronger absorbed $\mathrm{PM}_{2.5}$ capability; we made the researches that used the closed fumigated treatment plants of different species, the results showed also that plants have very strong absorbed $\mathrm{PM}_{2.5}$ ability, with the number of plant increase, the absorbing $\mathrm{PM}_{2.5}$ ability are obvious enhancement, then 4 plants, most of plants absorbed $\mathrm{PM}_{2.5}$ amount were $90-130 \mu \mathrm{g} / \mathrm{m}^{3}$, then 10 plants, most of plants absorbed amount of $\mathrm{PM}_{2.5}$ reached $120-175$ $\mu \mathrm{g} / \mathrm{m}^{3}$. So, try to protect present vegetation, and increase the area of plant community, and further reforming and optimizing the structure of plant community, can more and effectively raise the absorbing and reducing $\mathrm{PM}_{2.5}$ quantity, thereby achieved the goal which raise the air quality, constitute well ecological environment of city.

\section{Conflicts of Interest}

The authors declare no conflicts of interest regarding the publication of this paper. 


\section{References}

Burton, M. L., Samuelson, L. J., \& Pan, S. (2005). Riparian Woody Plant Diversity and Forest Structure along an Urban-Rural Gradient. Urban Ecosystems, 8, 93-106. https://doi.org/10.1007/s11252-005-1421-6

Chen, X. P., Jiao, Y. W., Pei, T. T., \& Zhou, Z. X. (2014). The Effect of Adsorbing Fine Particulate Matter (PM2.5) by Garden Plants. Chinese Journal of Ecology, 33, 2558-2566.

Gao, X. M., Huang, J. H., Wan, S. Q., \& Chen, L. Z. (1997). Ecological Studies on the Plant Community Succession on the Abandoned Cropland in Taibaishan, Qingling Mountains, II The Community $\alpha$-Diversity Feature of the Successional Series. Acta Ecologica Sinica, 17, 619-625.

Grobler, C. H., Bredenkamp, G. J., \& Brown, L. R. (2002). Natural Woodland Vegetation and Plant Species Richness of the Urban Open Spaces in Gauteng, South Africa. Koedoe, 45, 19-34. https://doi.org/10.4102/koedoe.v45i1.13

Huang, J. Y., Zhou, S. Q., Tan, Y. C., Zhou, X. P., Wang, P. Y., \& Zhang, H. M. (2007). Study on the Species Diversity of Plant Community in the Giant Panda Habitat of Wolong Natural Reserve: Species Richness, Species Diversity and Evenness. Scientia Silvae Sinicae, 43, 73-78.

Huang, Y. Y., Xu, B., Liang, H. et al. (2020). The Ecological Studies of Baguang Region in Shenzhen. China Forestry Press.

Huang, Y. Y., Yu, X. F., Liang, H., Zhao, K. S., Lu, Y. H., Chen, Y. H., Liu, N., Yang, L. J., Dong, A. Q., Ming, Z., \& Lai, B. W. (2016a). Studies on Vegetation Composition and Plant Diversity of Shenzhen Lianhua Mountain. Agricultural Research and Application, No. 2, 18-34.

Huang, Y. Y., Yu, X. F., Zhao, K. S., Yang, L. J., Liang, H., Lu, Y. H., Wang, H. Y., Liu, H., Ming, Z., Liu, N., \& Zhou, Z. B. (2016b). The Comparative Study on Plant Diversity of Xiaonanshan and Yingrenshi Mountain Area in Shenzhen, China. Guihaia, 36, 795-805.

Huang, Y. Y., Zhao, K. S., Yang, L. J. et al. (2017). Plant Community Structure and Plant Diversity of Mountain Areas in Shenzhen. Science Press.

Ji, J., Wang, G., Du, X. L., Jin, C., Yang, H. L., Liu, J., Yang, Q. L., Tchouopou, L. J., Li, J., \& Chang, C. T. (2013). Evaluation of Adsorbing Haze PM2.5 Fine Particulate Matters with Plants in Beijing-Tianjin-Hebei Region in China. Scientia Sinica Vitae, 43, 694-699. https://doi.org/10.1360/052013-154

Kang, J., Liu, W. Q., Yu, F. Q., Zhai, Q. J., \& Liao, W. B. (2005). Vegetation Types and Plant Community Characters in Bijiangshan Park in Shenzhen, Guangdong Province. Acta Scientiarum Naturalium Universitatis Sunyatseni, 44, 10-31.

Li, X. J., Song, Q. D., \& Chen, Q. B. (2008). The Resources and Community Characteristics of Vatica mangachapoi Blanco Forest in Bawangling Nature Reserve of Hainan Island. Forest Resource Management, No. 2, 85-89, 94.

Li, X. Q., Zhang, G. B., \& Chao, J. K. (2007). Study on Plant Species Diversity in the Forest Communities in Lingnan in Anhui Province. Journal of Jiangsu Forestry Science \& Technology, 24, 28-31.

Li, Z. S., Tang, J. W., Zheng, Z., Li, Q. J., Luo, C. K., Liu, Z. A., Li, Z. N., Duan, W. Y., \& Guo, X. M. (2004). A Study on Plant Diversity of Tropical Mountain Rain Forests Xishuangbanna, Yunnan. Acta Phytoecologica Sinica, 28, 833-843. https://doi.org/10.17521/cjpe.2004.0109

Liang, H., Huang, Y. Y., Lin, S. Z. et al. (2016). Study on Plant Diversity of Mountain Areas of Yangmeikeng and Chiao, Shenzhen, China. American Journal of Plant 
Sciences, No. 7, 2527-2552. https://doi.org/10.4236/ajps.2016.717220

Liu, J., Luo, L., Wu, G. P., Zhang, B., Zhan, H. L., \& Liao, W. B. (2010). Studies on Sinosideroxylon wightianum Communities in Dananshan Region of Shenzhen City, Guangdong Province, China. Journal of Tropical and Subtropical Botany, 18, 523-529.

Liu, M., Qiu, Z. J., Zhou, G. Y., \& Xu, H. (2007). Undergrowth Species Diversity of Acacia mangium Plantation in Phoenix Mountain, Shenzhen, China. Forest Science and Technology of Guangdong, 23, 26-31.

Mao, Z. H., \& Zhu, J. J. (2006). Effects of Disturbances on Species Composition and Diversity of Plant Communities. Acta Ecologica Sinica, 26, 2696-2701.

Ortega-Álvarez, R., Rodrıguez-Correa, H. A., \& MacGregor-Fors, I. (2011). Trees and the City: Diversity and Composition along a Neotropical Gradient of Urbanization. International Journal of Ecology, 2011, Article ID: 704084. https://doi.org/10.1155/2011/704084

Turner, B. L., Wells, A., Andersen, K. M., \& Condron, L. M. (2012). Patterns of Tree Community Composition along a Coastal Dune Chronosequence in Lowland Temperate Rain Forest in New Zealand. Plant Ecology, 213, 1525-1541.

https://doi.org/10.1007/s11258-012-0108-3

Wale, H. A., Bekele, T., \& Dalle, G. (2012). Plant Community and Ecological Analysis of Woodland Vegetation in Metema Area, Amhara National Regional State, Northwestern Ethiopia. Journal of Forestry Research, 23, 599-607. https://doi.org/10.1007/s11676-012-0300-2

Wang, D. P., Ji, S. Y., Chen, F. P., Xing, F. W., \& Peng, S. L. (2003). A Study on the Species Diversity and Succession Situation of Natural Forest Communities in Nanshan District, Shenzhen City. Acta Ecologica Sinica, 23, 1415-1422.

Wang, Y., Ouyang, Z. Y., Zheng, H., Chen, F., Chen, S. B., \& Zeng, J. (2013). Effects of Three Forest Restoration Approaches on Plant Diversity in Red Soil Region Southern China. Acta Ecologica Sinica, 33, 1204-1211. https://doi.org/10.5846/stxb201207080956

Zhang, J. T. (2011). Quantitative Ecology (The 2nd ed.). Science Press.

Zhang, Y. X., Chen, H. F., Qin, X. S., Zhang, R. J., \& Xing, F. W. (2007). Characteristics and Species Diversity of Syzygium odoratum Community in Dapeng Pninsula, Shenzhen. Guihaia, 27, 596-603.

Zhao, S. T., Li, X. Y., \& Li, Y. M. (2016). Capability of Common Garden Plants in Beijing to Retain PM(2.5). Journal of Northwest Forestry University, 31, 280-287.

Zhu, B., Chen, A. P., Liu, Z. L., Li, G. Z., \& Fang, J. Y. (2004). Changes in Floristic Composition, Community Structure, and Tree Species Diversity of Plant Communities along Altitudinal Gradients on Mt. Mao'er, Guangxi, China. Biodiversity Science, 12, 44-52. 